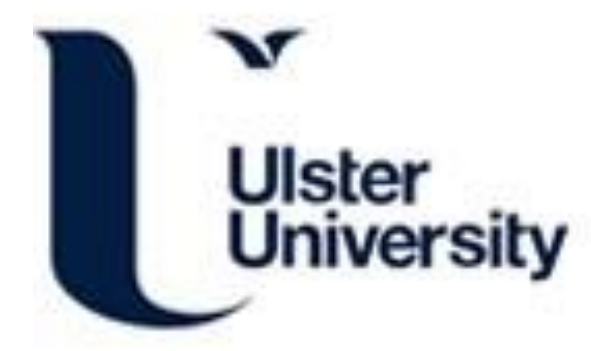

\title{
Techno-economic assessment of cascade air-to-water heat pump retrofitted into residential buildings using experimentally validated simulations
}

Le, K., Huang, M., Shah, N., Wilson, C., MacArtain, P., Byrne, R., \& Hewitt, N. (2019). Techno-economic assessment of cascade air-to-water heat pump retrofitted into residential buildings using experimentally validated simulations. Applied Energy, 250, 633-652. https://doi.org/10.1016/j.apenergy.2019.05.041

Link to publication record in Ulster University Research Portal

Published in:

Applied Energy

Publication Status:

Published (in print/issue): 15/09/2019

DOI:

10.1016/j.apenergy.2019.05.041

\section{Document Version}

Author Accepted version

\section{General rights}

Copyright for the publications made accessible via Ulster University's Research Portal is retained by the author(s) and / or other copyright owners and it is a condition of accessing these publications that users recognise and abide by the legal requirements associated with these rights.

\section{Take down policy}

The Research Portal is Ulster University's institutional repository that provides access to Ulster's research outputs. Every effort has been made to ensure that content in the Research Portal does not infringe any person's rights, or applicable UK laws. If you discover content in the Research Portal that you believe breaches copyright or violates any law, please contact pure-support@ulster.ac.uk. 


\title{
Techno-economic assessment of cascade air-to-water heat pump retrofitted into residential buildings using experimentally validated simulations
}

Khoa Xuan Le ${ }^{\mathrm{a}, *}$, Ming Jun Huang ${ }^{\mathrm{a}}$, Nikhilkumar N. Shah ${ }^{\mathrm{a}}$, Christopher Wilson ${ }^{\mathrm{a}}$, Paul Mac Artain ${ }^{\mathrm{b}}$, Raymond Byrne ${ }^{\mathrm{b}}$, Neil J. Hewitt ${ }^{\mathrm{a}}$

${ }^{a}$ Centre for Sustainable Technologies, University of Ulster, Co. Antrim BT37 0QB, United Kingdom ${ }^{b}$ School of Engineering, Dundalk Institute of Technology, Co. Louth A91 KS84, Ireland

\begin{abstract}
Cascade air-to-water heat pumps are designed to mitigate the problems of reduced heating capacity and efficiency, and high compressor ratios and discharge temperatures under low ambient temperatures for high temperature water supply. While many studies investigated the specific features of equipment performance of cascade heat pumps, little information is available in the literature about retrofit applications of these heat pumps in residential buildings using experimentally validated dynamic building simulations. In this study, the techno-economic assessment of a variable capacity cascade air-to-water heat pump retrofitted into residential buildings is conducted by means of experimentally validated TRNSYS simulations. The cascade heat pump coupled with thermal energy storage operating in different scenarios is further studied. Laboratory and field trial results were obtained to develop and validate a cascade heat pump model integrated with a dynamic building simulation model. Regarding the heat pump system without storage, the predicted annual COPs were almost below 2.5 under ambient temperatures of from $-11.2^{\circ} \mathrm{C}$ to $29.5^{\circ} \mathrm{C}$, even if the heat pump adopted weather compensation control. Simulation results also indicated that the cascade heat pump could not defeat gas boilers and high-efficiency oil boilers in terms of operating costs, but there were $\mathrm{CO}_{2}$ reductions (from 14\% to 57\%). As for the heat pump coupled with storage, simulation results showed that the continuous coupling between the heat pump and the storage revealed the lowest annual performance (actual COP of 1.41), while the direct heating obtained the highest efficiency (actual COP of 2.12) followed by the load-shifting (actual COP of 1.88).
\end{abstract}

The short version of the paper was presented at ICAE2018, Aug 22-25, Hong Kong. This paper is a substantial extension of the short version of the conference paper. 
Keywords: Cascade air-to-water heat pump, thermal energy storage, retrofit performance, TRNSYS simulation, energy performance, running costs, carbon emissions.

\section{Introduction}

In the European Union, buildings accounted for about $40 \%$ of the energy consumption and $36 \%$ of $\mathrm{CO}_{2}$ emissions [1]. In the UK, the domestic sector was responsible for $29 \%$ of total final energy consumption [2] and $16 \%$ of all carbon dioxide emissions [3]. Space and hot water heating demands comprised approximately $40 \%$ of total carbon emissions in this sector [4], and about $88 \%$ of these demands were provided by fossil-fueled boilers [5]. With the commitment to reducing greenhouse gas emissions up to $80 \%$ by 2050 compared to 1900 levels [6], many researchers and policy makers in the EU have focused on decarbonising space and hot water heating at the domestic level by using renewable-based alternatives, such as heat pumps.

Heat pumps have been used as a retrofit solution due to its high efficiency as well as capability to directly replace existing fossil-fueled boilers. Furthermore, an increasing portion of renewable electricity generation from renewable sources, such as solar, wind, etc., means heat pumps have increased potential to reduce carbon footprint as the carbon intensity in the grid has been considerably decreased [7]. For example, in the first six months of 2018 in the UK, there was a reduction of $19 \%$ in the electricity carbon emissions factor compared to the previous year [8]. Since ground source heat pumps have considerably higher initial costs than conventional heating systems (mainly due to the capital costs of the heat pump unit and the ground work) [9], air-to-water heat pumps (AWHPs) appear attractive for building retrofit.

\footnotetext{
*Corresponding author: Tel. +44 (0) 2890366413

Email address: le-k@ulster.ac.uk or k.le@ulster.ac.uk (Khoa Xuan Le)
} 


\section{Nomenclature}

$\triangle t_{\text {def }}$ period between defrost cycles or frosting time [minute]

$\dot{m} \quad$ volumetric flow rate $[l / s]$

$\bar{Y}_{\text {measure }}$ arithmetic mean of measured daily COP regarding $n$ observations [-]

$\rho \quad$ density of water $\left[\mathrm{kg} / \mathrm{m}^{3}\right]$

$a, b, c, d, f, g, h$ empirical coefficients obtained from polynomial regression $[-]$

$C_{p}$ water specific heat capacity $[\mathrm{kJ} / \mathrm{kg} \cdot \mathrm{K}]$

$C O P$ coefficient of performance of heat pump [-]

$C O P_{\text {sys }}$ coefficient of performance of heat pump system which accounts for heat loss of the system [-]

$C V(R M S E)$ coefficient of variations of the root mean square errors [-]

$E \quad$ Energy $[\mathrm{kWh}]$

EIR electric input ratio [-]

$f \quad$ cost function/normalized value [-]

$n$ number of observations [-]

$P L F$ part load factor [-]

PLR part load ratio [-]

$Q \quad$ thermal heat output $[\mathrm{kW}]$

$R H \quad$ ambient relative humidity [\%]
$T$ temperature $\left[{ }^{\circ} \mathrm{C}\right]$

$t_{\text {def }}$ time of a defrost cycle [minute]

$W \quad$ eletric input power $[\mathrm{kW}]$

$Y_{\text {measure }}$ measured daily COP [-]

$Y_{\text {sim }}$ simulated daily COP [-]

\section{Subscripts}

a ambient

act actual

$c \quad$ cooling

def defrost

e electric use

fr frosting

full full load

house house

$h p \quad$ heat pump

in inlet

inter interpolation

out outlet

pm performance map

$q$ heat

ref reference

req require

setpoint set point of model

$w \quad$ water 
While many studies conducted the performance of AWHPs when retrofitted into existing housing stock in different nations, most of them considered single-stage AWHPs reproducing low or medium flow temperatures (below $60^{\circ} \mathrm{C}$ ). For example, Madonna and Bazzocchi [10] used in-situ validated simulations to evaluate the annual performance of reversible AWHPs in small residential dwellings in Italy. The supply temperatures were limited to $45^{\circ} \mathrm{C}$. Asaee et al. [11] assessed the techno-economic feasibility of retrofit AWHPs for the Canadian housing stock. The space and domestic hot water (DHW) heating was provided from two stages. The first stage was supplied by the AWHPs to provide the outlet water temperature of $50^{\circ} \mathrm{C}$, and then the $50^{\circ} \mathrm{C}$ water flow was heated in the second stage to a maximum of $55^{\circ} \mathrm{C}$ by auxiliary boilers. The study found that the reductions of $36 \%$ of energy consumption and $23 \%$ of green house gas emissions could be achieved if all eligible houses were retrofitted by the single-stage AWHPs. In Germany, the field test results of 21 single-stage AWHPs and 22 brine-to-water GSHPs were gathered to evaluate the heat pumps' retrofit performance [12]. The tested heat pump systems comprised the heat pump units providing hot water floor heating and/or radiators with the flow temperatures of $40^{\circ} \mathrm{C}$ and $55^{\circ} \mathrm{C}$, respectively. In the UK, Kelly and Cockroft [7] evaluated the running costs and carbon emissions of single-stage AWHPs when retrofitted into domestic dwellings in Scotland. The retrofit AWHPs fed hot water radiators with the nominal flow temperature of $55^{\circ} \mathrm{C}$, whereas $\mathrm{DHW}$ was supplied separately by electric heating coils. The authors concluded that the retrofit AWHPs could obtain $12 \%$ carbon savings compared to condensing gas boiler systems, but there was a cost penalty of $10 \%$ to operate the heat pumps. Cabrol and Rowley [13] conducted a comparative analysis of the UK domestic buildings with the integrated system of underfloor heating and single-stage AWHPs. Both the Energy Saving Trust (EST) and Department of Energy and Climate Change (DECC) [14] investigated two main field trials for single-stage AWHPs and GSHPs in the UK, and both field trials considered outlet water temperatures between $30^{\circ} \mathrm{C}$ and $55^{\circ} \mathrm{C}$.

However, using single-stage AWHPs as a retrofit alternative is unlikely to be a feasible solution in practice. This is because $35 \%$ of the EU's buildings [1] and 27.5 million UK's residential houses [15] are ageing, heavily relying on conventional boilers with high temperature (over $60^{\circ} \mathrm{C}$ ) heating distribution systems (wet radiator systems) to supply space and hot water heating demands. Indeed, the existing high temperature wet radiators were designed to work efficiently with the flow temperature of $75^{\circ} \mathrm{C}$ as suggested by BS-EN 442-2:2014 [16]. In order to provide this high outlet water temperature, the condensing temperature in single-stage AWHPs should be kept at a high level, which leads to high compression 
ratios and high compressor discharge temperatures as stated by Jung et al. [17]. Besides, at low ambient temperatures, the efficiency and heat capacity of an air source heat pump water heating decrease when attempting to lift its outlet water temperatures above $60^{\circ} \mathrm{C}$ [18]. Therefore, replacing existing boilers with single-stage heat pumps in the housing stock of the EU, particularly the UK, is more difficult because it requires the adjustment of the heat distribution systems, which results in high installation costs and disruptions when retrofitting. Furthermore, recent field trials [14] and previous studies [7] [13] investigated the techno-economic performance of retrofit single-stage AWHPs in the UK with the compromise of using oversized or underfloor radiators; however, the authors did not consider the installation costs.

Cascade AWHPs, in which there are two separate compressors employing different refrigerant fluids, can address the problems of high compressor ratios and high discharge temperatures occurring in single-stage AWHPs when attempting to lift the outlet water temperatures to high levels [17]. The study of Bertsch and Groll [19] also showed that cascade compression systems obtained better performance at low external air temperatures. As a result, cascade AWHPs may be a potential solution for retrofit application in the UK since they can directly replace existing boilers without the requirement of considerable modifications to the heat distribution systems, thereby reducing installation costs and disruptions compared to single-stage AWHPs.

The number of studies on cascade AWHPs for space and hot water heating has increased recently, according to the extensive reviews of Chua et al. [20], Willem et al. [21] and Zhang et al. [22]. However, most of the previous studies focused on the specific aspect of device performance. For example, Jung et al. [17] carried out experiments to compare the performance between a cascade multi-functional AWHP and a single-stage multi-functional AWHP providing space and hot water heating. The performance of the cascade heat pump was measured by adjusting the refrigerant charge amount, electronic expansion valve opening, water flow rate, and water inlet temperature. Park et al. [23] developed a mathematical model, validated against laboratory results, to investigate the thermodynamic analysis of a cascade refrigeration system with R134a and R410A to find the optimal intermediate temperature. The author and co-workers later developed another experimentally validated steady-state cascade heat pump model coupled with a water storage tank model to assess the transient behavior of the system [24]. Soltani et al. [25] modelled and compared three AWHP systems, including single-stage, single refrigerant cascade and two-refrigerant cascade, to ascertain the suitability of cascade heat pumps for hydronic residential systems. 
Kim et al. [26] carried out a numerical and experimental study of a cascade AWHP adopting R134a and R410A refrigerant to optimize intermediate temperature of the system. These authors also conducted another study about the effect of the refrigerant charge amount on single and cascade cycle heat pump systems by means of numerical and experimental approaches [27]. Kim and Kim [28] studied experimentally how water temperature lift affected the pressure and performance of a cascade AWHP using R134a and R410A. Ma et al. [29] investigated how other working fluids (BY-3 in the low-stage refrigerant cycle and R245fa in the high-stage refrigerant cycle) influenced cascade AWHPs. Wu et al. [18] experimentally evaluated the transient behaviour and dynamic performance of a cascade AWHP system operating with and without phase change material storage tank. This study also compared the performance between single-stage mode and cascade mode. Wang et al. [30] developed a cascade AWHP system in which the heat of the two-stage cycles was exchanged by a circulating water loop. This heat pump system was then tested in a field trial located in the northwest suburb of Beijing, China, with the aim to enhance the working condition and heating performance under cold climates.

Whilst there are many studies on cascade AWHPs investigating the specific feature of equipment performance as mentioned above, little information about cascade AWHPs for the real retrofit application in residential buildings, especially attempting to quantify energy and carbon savings, is available in literature. Recently, the UK Department for Business, Energy and Industrial Strategy [31] released a technical report aiming to investigate the retrofit potential of domestic high temperature air source heat pumps for space and hot water heating. This research was carried out by gathering short-term field trial results in different sites across the UK. Another study by Shah et al. [32] conducted field trials of a cascade AWHP integrated with a thermal energy storage (TES) tank to highlight its retrofit performance in the UK, but again the field trials were carried out in short periods. Shortterm field trials alone could not accurately evaluate the potential costs and carbon savings of these heat pumps because AWHPs' performance is sensitive to seasonal and boundary conditions. Therefore, experimentally validated modelling and simulations are needed to further evaluate the potential costs and carbon savings of this technology.

According to the reported literature, much research has developed the model of cascade AWHPs validated against laboratory and field data, but most of the modelling work was carried out for equipment performance rather than integrated performance with buildings. To the best of our knowledge, there is no study conducting experimentally validated cascade AWHPs coupled with the dynamic building simulation model to investigate its full-scale 
retrofit performance.

In recent years, thermal energy storage (TES) coupled with heat pumps has significant merits for demand-side management that may play a considerable role in future energy systems with increased proportions of non-dispatchable renewable energy [33]. This system can be used as a mean for shifting load from peak-demand to low-demand periods, which can help to balance the grid and reduce electricity bills for end-users when taking advantage of electricity tariffs [34]. In addition, TES combined with heat pumps is potential to increase buildings' energy efficiency [35]. Although there are many merits that this combined system can bring to, there is little information about the performance of cascade AWHPs integrated with TES in residential dwellings as a demand-side management for space heating and domestic hot water.

In this paper, the modelling and simulations of a variable capacity cascade AWHP and TES coupled with a typical residential building, validated against laboratory and field results, are presented. TRNSYS 17 software [36] was used to develop and simulate the models. This study obtained part of the field trial results mentioned in the previous paper [32] for developing and validating the models. The aims of this work were twofold. The first was to evaluate the retrofit performance of the stand-alone cascade AWHP system (without TES) in the UK residential buildings, especially endeavoring to quantify carbon and energy savings compared with oil and gas fired boilers. Another aim was to assess how the system of the retrofit cascade AWHP coupled with TES performs in different configurations in a residential dwelling. The following sections explain in detail how this research was carried out.

\section{Experiment description}

\subsection{The selected cascade air to water heat pump}

The reference cascade AWHP (CAWHP) was a commercially available unit. The outdoor unit using R-410A refrigerant extracted heat from the ambient and then transferred to the indoor unit employing R-134a refrigerant via intermediate heat exchangers. According to the manufacturer's catalogue, the heat pump had a nominal COP of 2.5 with the nominal heating capacity of $11 \mathrm{~kW}$ at $7^{\circ} \mathrm{C}\left(44.6^{\circ} \mathrm{F}\right)$ dry-bulb temperature $/ 6^{\circ} \mathrm{C}\left(42.8^{\circ} \mathrm{F}\right)$ wet-bulb temperature of the outdoor unit, and $80^{\circ} \mathrm{C}\left(176^{\circ} \mathrm{F}\right)$ outlet water temperature of the indoor unit [37]. The selected CAWHP employed capacity control, meaning its thermal output can be modulated depending on the required thermal load. It is worth noting that a pump 
circulating hot water from the condenser heat exchanger to the load side was installed inside the indoor unit, which was designed by the manufacturer.

\subsection{Laboratory experiment}

The selected CAWHP was previously tested in the laboratory, with the outdoor unit mounted inside a climatic chamber (Fig. 1). Within the chamber, the air temperatures and humidity were maintained at specific levels, while the indoor unit was located outside the chamber. The indoor unit was connected with a dedicated water circuit, including a heat exchanger, a storage tank, a three way valve, an actuator and a PID controller, to keep the inlet and outlet water temperature of the heat pump constant during the tests.

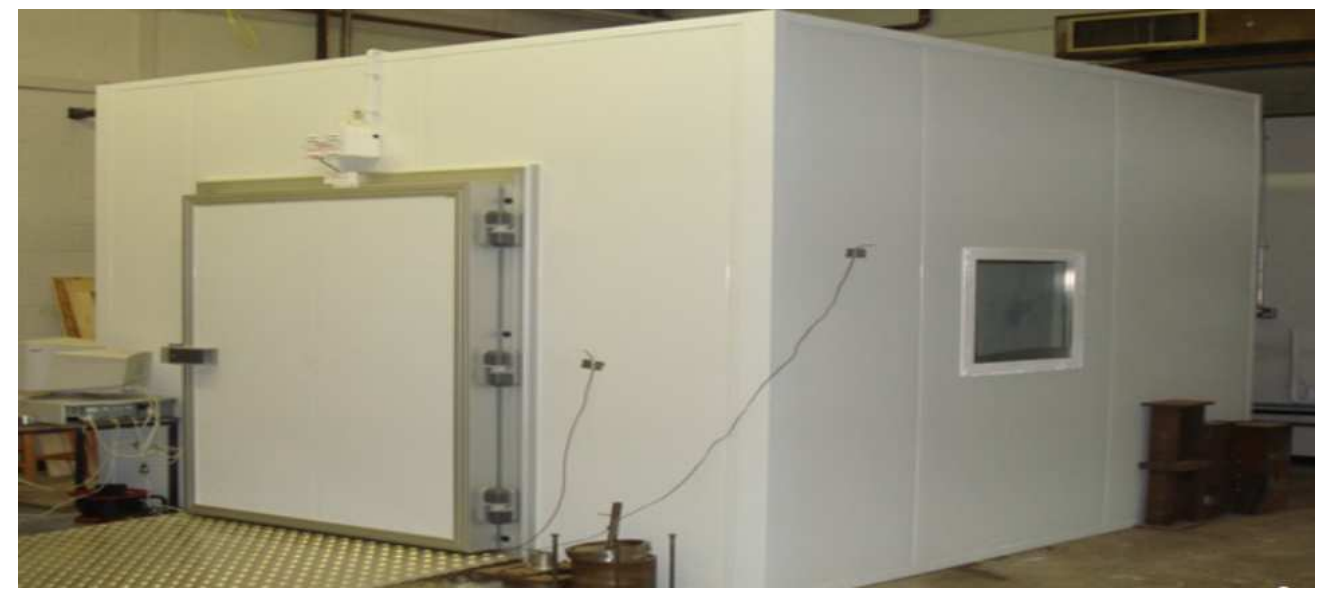

Figure 1: Climatic chamber used for testing the heat pump.

The heat pump was tested following the conditions suggested by the European Standard EN14511 - Part 3 [38]. The testing conditions are reported in Table 1. The inlet and outlet water temperature, water flow rate and electric consumption of the heat pump were measured using the instruments mentioned in Table 2. It is worth noting that the electric consumption of the heat pump outdoor and indoor units were measured directly by two energy meters, which accounted for the total consumption of the two compressors, controllers, valves, fans and a circulating pump inside the indoor unit. 
Table 1: Heat pump testing conditions in the lab.

\begin{tabular}{ccccc}
\hline$T_{a}\left({ }^{\circ} \mathrm{C}\right)$ & $T_{w, \text { out }}\left({ }^{\circ} \mathrm{C}\right)$ & $T_{w, \text { in }}\left({ }^{\circ} \mathrm{C}\right)$ & $\mathrm{RH}(\%)$ & $\dot{m}(\mathrm{l} / \mathrm{s})$ \\
\hline 2 & 55 & 45 & 76 & 0.34 \\
7 & 55 & 45 & 76 & 0.33 \\
12 & 55 & 45 & 76 & 0.36 \\
2 & 65 & 55 & 76 & 0.32 \\
7 & 65 & 55 & 76 & 0.37 \\
12 & 65 & 55 & 76 & 0.37 \\
2 & 75 & 65 & 76 & 0.36 \\
7 & 75 & 65 & 76 & 0.39 \\
12 & 75 & 65 & 76 & 0.42 \\
\hline
\end{tabular}

Table 2: Measuring instruments and uncertainty ranges.

\begin{tabular}{lcc}
\hline Instrument & Type and model & Uncertainties \\
\hline Fluid temperature & Inline and Surface PT 100, Eltek GD24 & $\pm 0.3^{\circ} \mathrm{C}$ \\
Flow meter & Electromagnetic, Eltek GC 62 & $\pm 1.5 \%$ \\
Electric consumption meter & Landis and Gr P350 & $\pm 1.5 \%$ \\
\hline
\end{tabular}

\subsection{Field trial experiment}

Two mid-terraced "hard to heat" buildings with 1900s design specifications were built at Jordanstown campus of Ulster University to investigate retrofit technologies in the UK. The buildings represented typical ageing houses in the UK that accounted for $27.3 \%$ of dwelling stocks in Northern Ireland [39] and $43 \%$ of the total stock in England [40]. The building to the right in Fig. 2 is named "House 63", and the one to the left is called "House 64". This study focused on the "House 64" inhabited by three people and retrofitted by a variable capacity CAWHP coupled with TES which provided heat for space heating and domestic hot water (DHW), as shown in Fig. 3. Before the retrofit CAWHP was installed, the house was equipped with a gas boiler transferring heat directly to DHW and conventional wet radiators for space heating with the nominal flow of $75^{\circ} \mathrm{C}$ via insulated cooper pipes. In this study, the heat distribution system remained, while the boiler was replaced by the CAWHP. The ground floor comprised living and kitchen areas, while the first floor included three bedrooms and a bathroom. Capacity of the DHW tank was 162 litres with the inner heat exchanger coil area of $0.88 \mathrm{~m}^{2}$ and maximum standing heat loss of $2.74 \mathrm{kWh} / 24 \mathrm{hrs}$. 


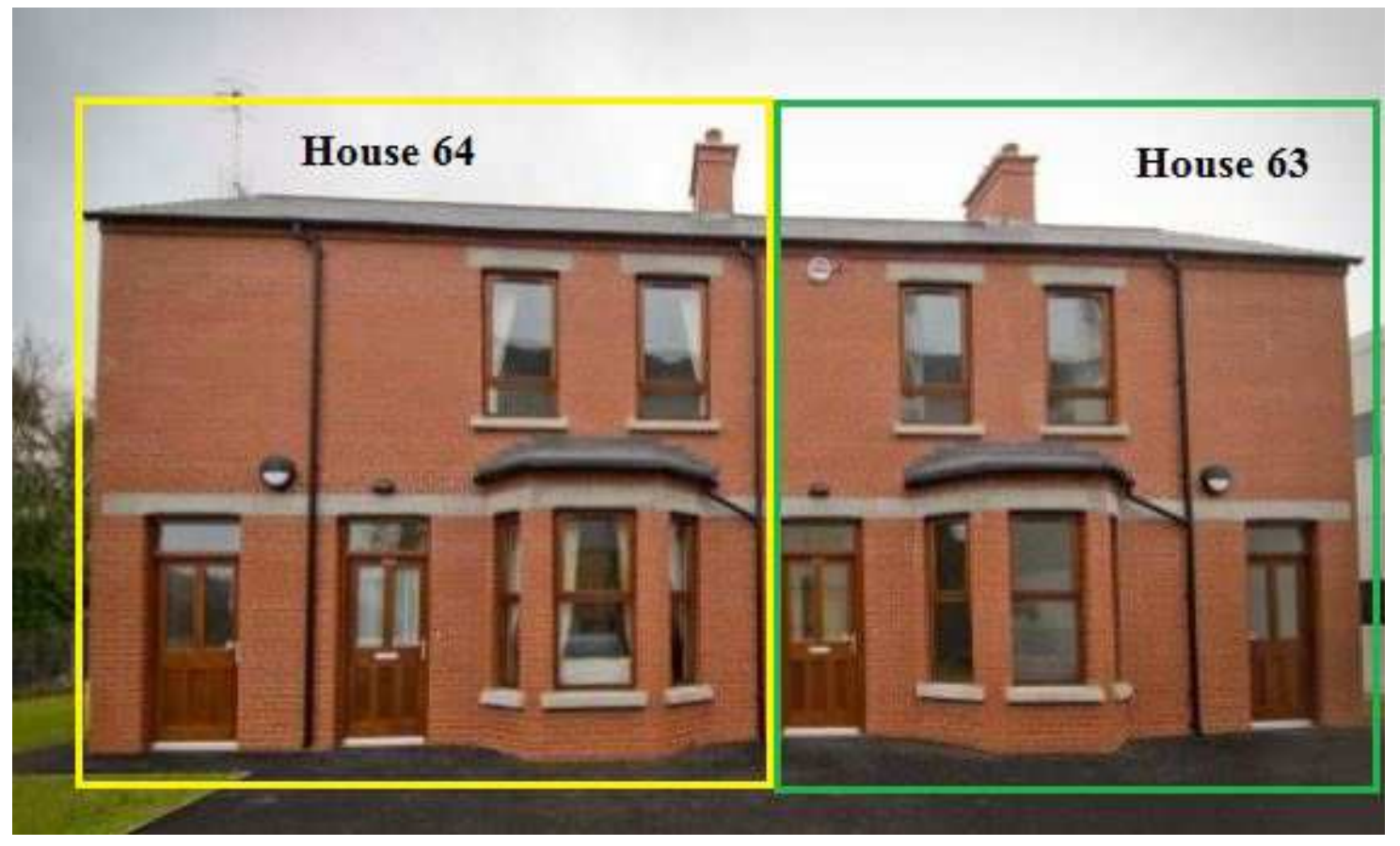

Figure 2: Two mid-terraced houses used for testing the retrofit CAWHP heat pump.

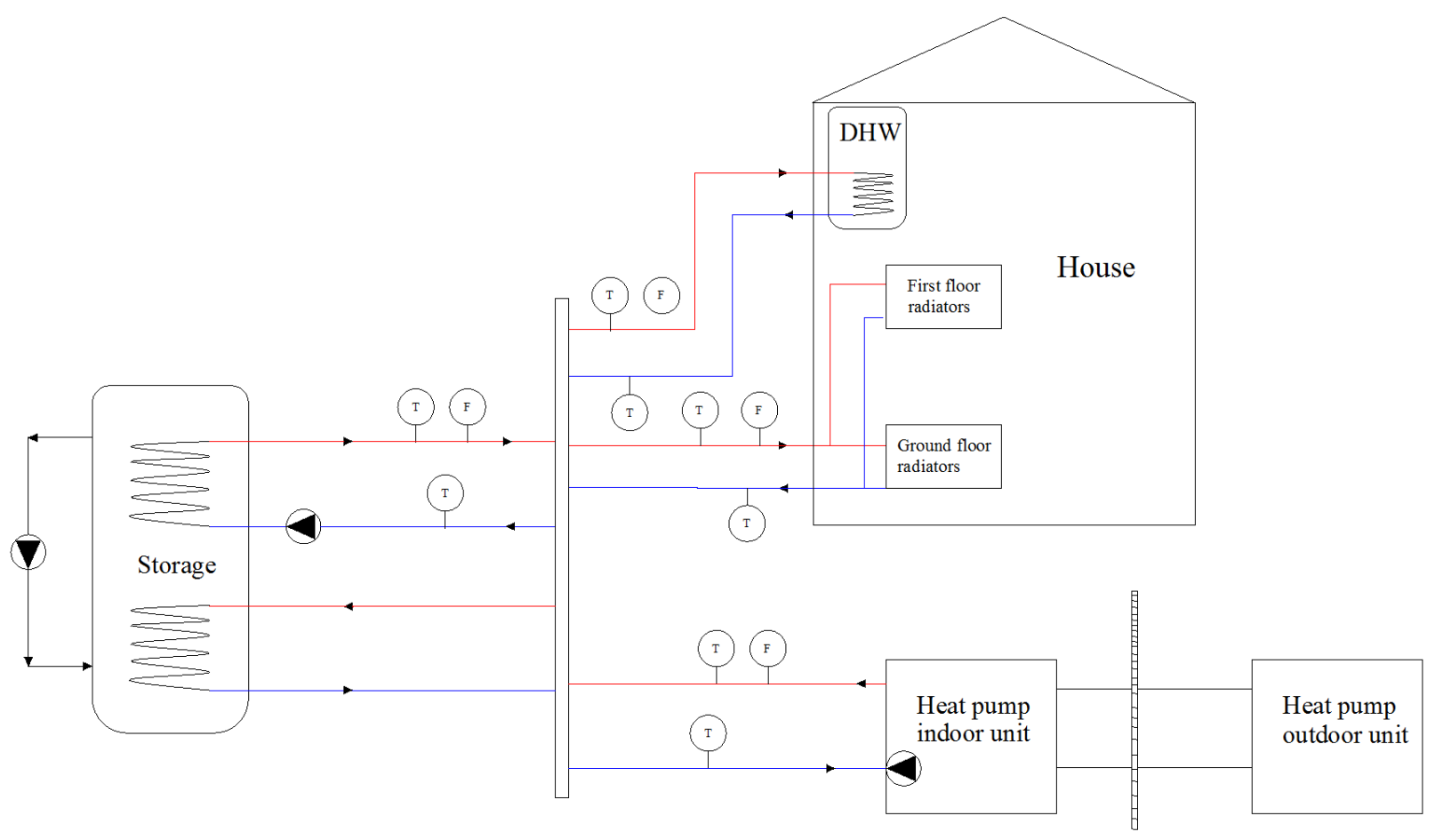

Figure 3: Schematic of the CAWHP system for space heating and hot water supply with thermal sensors and flow rate monitoring.

The TES was a custom made sensible vertical cylinder. The storage was copper material, 600-liter capacity, $2 \mathrm{~m}$ height and $0.6 \mathrm{~m}$ diameter, and contained water as the storage medium. The tank was insulated with $75 \mathrm{~mm}$ thick foam. The charging heat exchanger coil connecting 
to the heat pump was placed at the bottom part, whilst the discharging coil supplying heat to the house was at the upper part of the tank. In this study, stratification occurring naturally within the sensible TES was eliminated by using a de-stat pump installed on the storage to mix thermally fully inside the tank.

The heating system was controlled by a scheduled programmer combined with a thermostat placed in the dining room. The occupants were able to choose the set point room temperature and the operation time whenever they preferred. They could also freely open windows and doors as well as occupy the house.

For the purpose of this study aiming at assessing the performance of a stand-alone retrofit CAWHP system and its integration with TES, the field trial results of the monitoring campaigns mentioned in the previous study of Shah et al. [32] were subdivided into three sessions that are described as follows:

- The first session, named Direct Mode, from 26/11/2014 to 10/02/2015: The heat pump delivered heat directly to the house. The outlet water temperature of the CAWHP was set to $75^{\circ} \mathrm{C}$ similar to the outlet of the replaced gas boiler.

- The second session, named Indirect Mode, from 21/02/2015 to 30/03/2015: The CAWHP provided heat to the TES tank, and that heat was then transferred to the house. The heat pump was switched on to reheat the tank if the average tank temperature was below $65^{\circ} \mathrm{C}$, and it was off when the tank reached $70^{\circ} \mathrm{C}$. This session can be known as a buffering system.

- The third session, called Combined Mode, between 16/04/2015 and 07/06/2015: The heat pump was switched on at lam (night time) to store energy in the TES, bringing the tank temperature to $75^{\circ} \mathrm{C}$. When the house required the first heating demand of the day, the stored energy was delivered to the house until its temperature dropped to $55^{\circ} \mathrm{C}$. After that, the heat pump took over to provide heat to the house for the rest of the day. This operation can be assigned as demand-side management (load shifting) in which the heat pump was shifted to off-peak hours (night time) with cheap electricity prices (Economy 7 tariff [41]) to store the energy which was later used in the peak demand of the day (in the early morning).

The monitoring campaigns concentrated on the performance of the CAWHP system. Therefore, the following parameters were measured:

- Heat output of the heat pump and heat input to the house were calculated using flow rates, water inlet and outlet temperatures recorded from the sensors shown in Fig. 3. 
- Electric use of the heat pump outdoor and indoor units was measured directly by two energy meters. Again, it is noted that the electric consumption of the two compressors, controllers, valves, fans and a circulating pump inside the indoor unit was totally accounted for.

A wireless radio data logger and 15 transmitters with built-in sensors (Table 2) were employed to monitor the system. Data was logged in one-minute intervals by means of a desktop computer-based data acquisition.

\subsection{Data elaboration and uncertainty analysis}

COP of the heat pump can be determined using Eq. 1, while COP of the whole system is calculated using Eq. 2 which accounts for the heat losses in each monitoring session.

$$
\begin{gathered}
C O P=\frac{E_{q, h p}}{E_{e}}=\frac{\int_{0}^{t} \rho \times C_{p} \times \dot{m}_{h p} \times\left(T_{w, \text { out }, \text { } p}-T_{w, \text { in }, h p}\right) \times \mathrm{d} t}{E_{e}} \\
C O P_{\text {sys }}=\frac{E_{q, \text { house }}}{E_{e}}=\frac{\int_{0}^{t} \rho \times C_{p} \times \dot{m}_{\text {house }} \times\left(T_{w, \text { in }, \text { house }}-T_{w, \text { out }, \text { house }}\right) \times \mathrm{d} t}{E_{e}}
\end{gathered}
$$

The uncertainties of the sensors used in the measurements are reported in Table 2. With the ignorance of the data acquisition system's errors, the uncertainty analysis of the measurements on the basis of sensors' errors was investigated using the method suggested by Holman [42]. Therefore, relative uncertainty of the thermal energy output and COP were found $\pm 5.17 \%$ and $\pm 5.59 \%$, respectively.

\section{Modelling}

In this work, TRNSYS 17 [36] was used to model and simulate the system, shown in Fig. 3, to meet the research objectives. TRNSYS is a transient system simulation tool in which individual components called "types" are linked to each other to model the energy performances of the HVAC systems, of which their behaviors are highly complex. Details of the developed models are given as follows.

\subsection{Cascade air to water heat pump model}

TRNSYS Type 1217 (non-standard TESS library component [43]) was used to model the performance of the reference variable capacity CAWHP. This model can be categorized as a "black box" that relies on a performance map containing full load and part load curves. The performance map is the heart of the heat pump model Type 1217, and thus obtaining the performance curves is a considerate task. In our case, the performance data provided 
by the manufacturer and the laboratory results contained nominal values from standard tests, which were different compared to field operations in the manner that the operation ranges were limited. Also, no data about the part load operation was available from the manufacturer. Therefore, the data collected from the field trial monitoring were used for performance map creation. This characterized performance map can allow the model to be performed like the real operation; however, note that the model accounted for steady-states only.

Regarding Type 1217, the parameters stated in the performance map were heat capacity and electric input power as the functions of ambient temperatures, desired outlet water temperatures, and more importantly, part load ratios at which the heat pump operated to maintain the user-specified outlet water temperatures regardless of alterations in inlet water temperatures or external air conditions [43]. Once the performance map was known, a series of calculations were performed. First, the heat $\left(Q_{r e q}\right)$ required to bring the inlet water temperature up to the user-defined outlet water temperature at the condenser side was calculated using Eq. 3. Then, the model determined the actual heat $\left(Q_{a c t}\right)$ delivered to water by means of comparing the calculated required heat $\left(Q_{r e q}\right)$ in Eq. 3 with the heat capacity returned by the data interpolation routine $\left(Q_{\text {inter }}\right)$, as expressed in Eq. 4. After that, the outlet water temperature was estimated using Eq. 5.

$$
\begin{gathered}
Q_{\text {req }}=C_{p} \times \dot{m} \times\left(T_{w, \text { setpoint }}-T_{w, i n}\right) \\
Q_{a c t}=\operatorname{Minimum}\left(Q_{\text {inter }}, Q_{r e q}\right) \\
T_{w, \text { out }}=T_{w, \text { in }}+\frac{Q_{a c t}}{\dot{m} \times C_{p}}
\end{gathered}
$$

To build the performance map and a defrost model, the recorded raw data regarding the heat pump from three monitoring sessions mentioned in section 2.3 were processed using $\mathrm{R}$ (programming language) software [44] and the suggested procedure of Underwood et al. [45], as explained as follows:

- The one-minute interval data in three monitoring sessions were gathered into one file, and null value rows indicating when the heat pump was switched off were discarded from the file.

- The processed data were then divided into two separate files. The first data file was used for creating the performance map of the heat pump model, with all data rows 
describing defrost cycles being removed (defrost events were observed by abnormal low and negative thermal output during steady state periods at low outdoor air temperatures and high relative humidity). The second file retained these defrost data to develop the defrost model.

The following subsections demonstrate in detail the performance map creation (including full load and part load curves) and the defrost model based on the two data files.

\subsubsection{Full load curves}

To build the full load curves of the variable capacity CAWHP model, the monitoring results of the first data file regarding thermal output and electric input power as the functions of external air temperatures were analyzed. Fig. 4 shows the monitoring data of the heat pump producing outlet water temperature of $75 \pm 1^{\circ} \mathrm{C}$ that was the set flow temperature used in the field trial. Note that the electric input power of the compressors, fans, controllers and a circulating pump was totally accounted for in the performance curves due to the field measurement set-up, as explained in section 2.3. In Fig. 4, data points are coded with color gradient referring to DeltaT that is the difference between outlet and inlet water temperatures at the heat sink. It can also be seen in the figures that the higher DeltaT, the higher thermal output and electric input power (except some spikes caused by transient states), which represent the higher load operation of the heat pump.
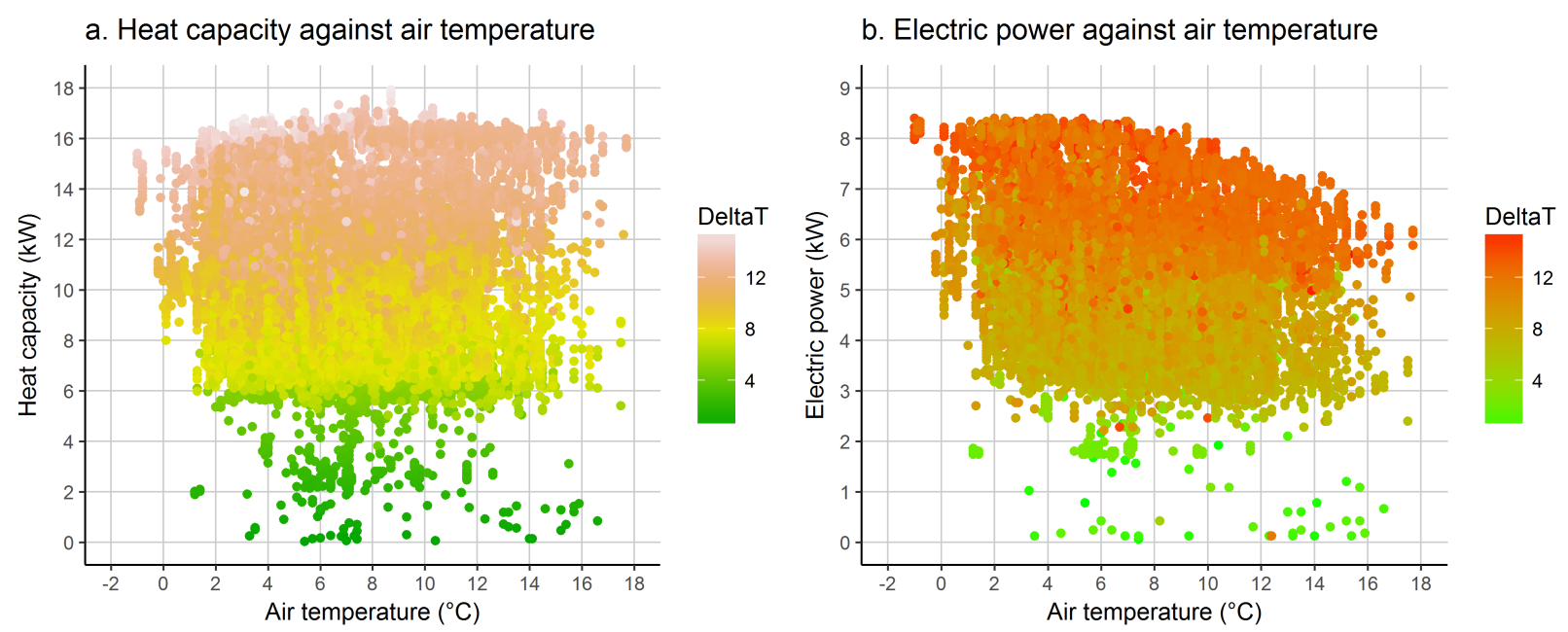

Figure 4: Monitoring results of heat and electric power versus air temperatures with outlet water temperature of $75 \pm 1^{\circ} \mathrm{C}$ (DeltaT is the difference between outlet and inlet water temperatures).

Since there were not enough data for sampling with small intervals of DeltaT (e.g. $13^{\circ} \mathrm{C}-$ $14^{\circ} \mathrm{C}$, or $14^{\circ} \mathrm{C}-15^{\circ} \mathrm{C}$ ) to accurately develop the maximum load curves, all data points with DeltaT $\geq 12^{\circ} \mathrm{C}$ were screened to analyze the full load curves, as illustrated in Fig. 5. The 
trends of median values of box plots in both graphs in Fig. 5 are likely to form regression lines. Therefore, after removing outliers observed in the whisky box plots (these random spikes related to transient states when the heat pump was switched on or off), the regression lines of the median values were then assumed as the full load curves of the heat pump model for the outlet water temperature of $75^{\circ} \mathrm{C}$.
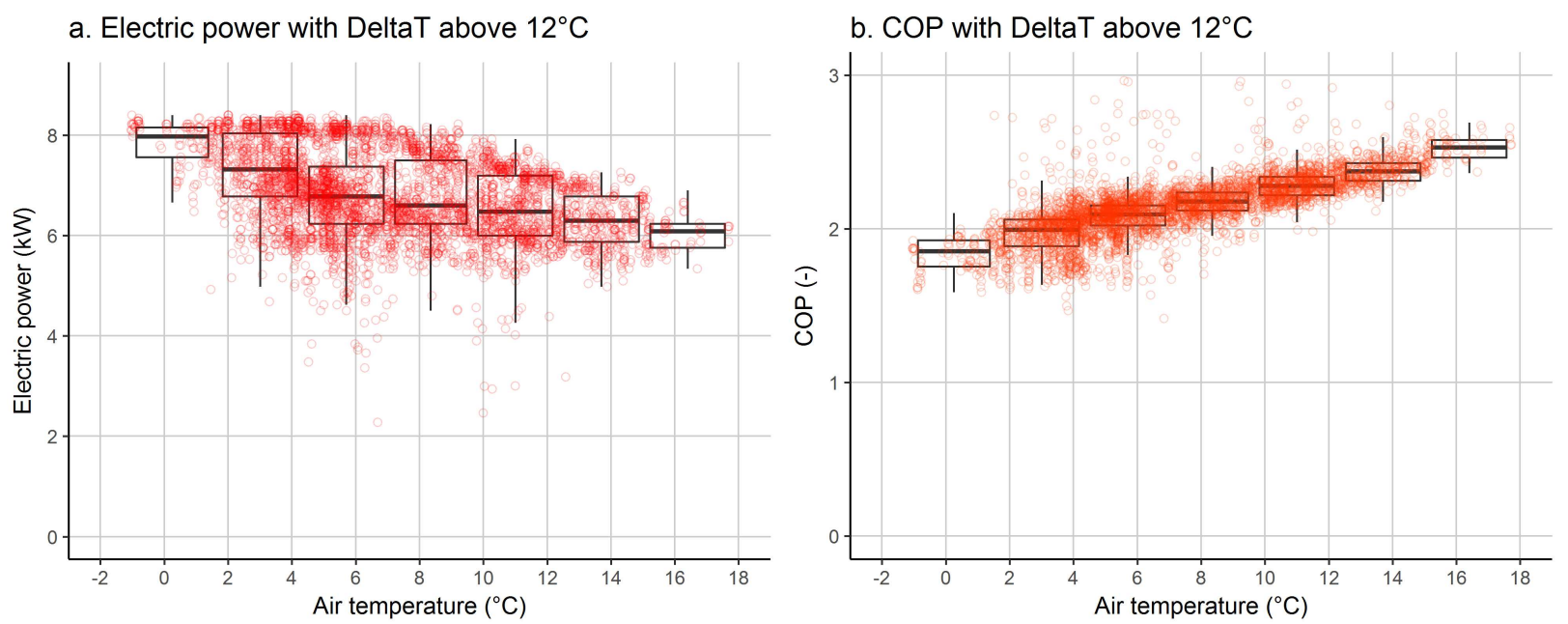

Figure 5: Monitoring results of electric input power and COP against air temperature with DeltaT $\geq 12^{\circ} \mathrm{C}$ and outlet water temperature of $75 \pm 1^{\circ} \mathrm{C}$.

Analysis using the same approach for the rest of the data on other outlet water temperatures produced a characterized performance map for full load operation for the heat pump model. The empirical correlations of the obtained full load curves are defined in the following Eq. 6 and Eq. 7 where the heat capacity $\left(Q_{\text {full }}\right)$ and compressor electric power $\left(W_{\text {full }}\right)$ at full load operation are the functions of external air temperatures $\left(T_{a}\right)$ and desired outlet water temperatures $\left(T_{w, \text { out }}\right)$. These equations were received from polynomial regression surface.

$$
\begin{gathered}
Q_{\text {full }}=-451+21 \times T_{w, \text { out }}-1.14 \times T_{a}-0.03 \times T_{w, \text { out }}^{2}-0.009 \times T_{a}^{2} \\
+0.001 \times T_{w, \text { out }}^{3}+0.03 \times T_{w, \text { out }} \times T_{a}-0.0002 \times T_{w, \text { out }}^{2} \times T_{a} \\
W_{\text {full }}=-1.01+0.7 \times T_{w, \text { out }}+0.24 \times T_{a}-0.01 \times T_{w, \text { out }}^{2} \\
+0.000051 \times T_{w, \text { out }}^{3}-0.0105 \times T_{w, \text { out }} \times T_{a}+0.000075 \times T_{w, \text { out }}^{2} \times T_{a}
\end{gathered}
$$

\subsubsection{Part load curves}

The retrofit CAWHP can ramp up or down its thermal output to maintain the desired outlet water temperature. As part load operation highly influences the heat pump efficiency, the model needs to take this effect into consideration. 
Fig. 6 depicts the part load curves of the heat pump to maintain the outlet water temperature of $75^{\circ} \mathrm{C}$, with part load ratio (PLR), electric input ratio (EIR) and part load factor (PLF) being expressed in the following Eq. 8-10. The part load curves shown in Fig. 6 were developed based on the first data file and assumed to be identical for the heat pump model. It can be seen from the figure that the highest efficiency can be obtained if the heat pump operates at about $85 \%$ of the maximum heat load.

$$
\begin{gathered}
P L R=\frac{Q}{Q_{\text {full }}} \\
\text { EIR }=\frac{W}{W_{\text {full }}} \\
P L F=\frac{C O P}{C O P_{\text {full }}}
\end{gathered}
$$

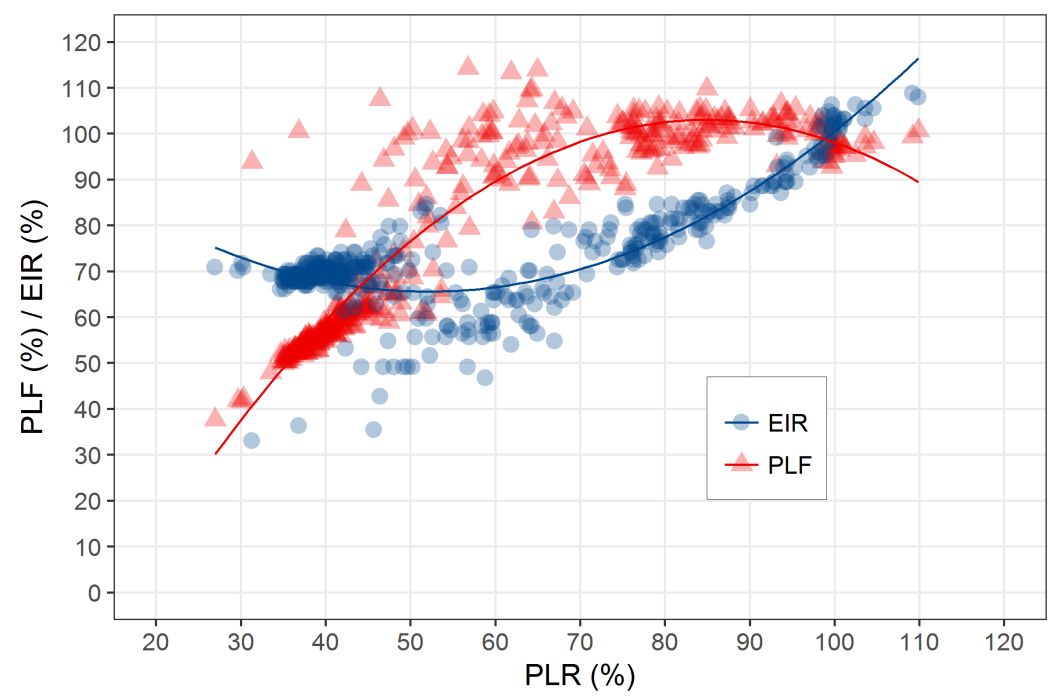

Figure 6: Part load curves obtained from monitoring results.

\subsubsection{Normalized curves}

The full load and part load curves mentioned above were normalized to let the TRNSYS Type 1217 heat pump model understand the declared performance map, which was required by the TRNSYS developer, as expressed in the following Eq. 11 and 12. The heat capacity $\left(Q_{\text {ref }}\right)$ and electric input power $\left(W_{\text {ref }}\right)$ values at the external air temperature of $7^{\circ} \mathrm{C}$ in accordance with the outlet water temperature of $75^{\circ} \mathrm{C}$ were chosen as reference values, being $14.95 \mathrm{~kW}$ and $6.48 \mathrm{~kW}$, respectively. These values were set up in the initial model and calibrated later as detailed in section 4.1.1. 


$$
\begin{gathered}
f_{q}=\frac{Q_{p m}}{Q_{r e f}} \\
f_{e}=\frac{W_{p m}}{W_{r e f}}
\end{gathered}
$$

\subsubsection{Incorporating defrost}

The heat pump model, Type 1217, was initially developed utilizing the collected performance data that excluded the periods of defrost operation (the first data file). Subsequently, a model accounting for defrost operation was developed based on the second data file and integrated outside the heat pump model.

When frost is formed on the surface of the evaporator heat exchanger, the heat pump's performance is reduced, and the compressor may be damaged because frost accumulation on the evaporator coil acts as a thermal insulator in addition to reducing air flow passage [10]. To address this problem, AWHPs need to activate defrost cycles periodically to melt ice on the outdoor evaporator coils. Reverse cycle (reversing refrigerant fluid) is a popular defrost method, and it was also adopted in the selected CAWHP. As designed by the manufacturer, both the indoor and outdoor refrigerant cycles will reverse if the reference CAWHP system is in a defrost mode of operation. In particular, the indoor unit takes heat from the water circuit to help provide heat for the outdoor unit via the intermediate heat exchanger, then the outdoor unit utilises this heat to help melt the ice on its outdoor coils.

Modelling defrost operation regarding reverse cycle is challenging [46]. Particularly, the frequency and duration of a defrost cycle are often difficult to predict because the rate of frost growth on the evaporator coil are affected by three main factors that cannot be determined sufficiently: (1) outdoor air conditions; (2) characteristics of the AWHPs (e.g. outdoor heat exchanger geometry [47], outdoor fan speed [48]); and (3) operating conditions (e.g. thermal load). Therefore, the proposed defrost model in this study was simplified using empirical correlations obtained from the monitoring results. When the outdoor air temperature was below $7^{\circ} \mathrm{C}$ and relative humidity was above $65 \%$ for a long period, the heat pump terminated heating to activate defrost operation. Note that these findings were similar to the works of Underwood et al. [45] and Madonna and Bazzocchi [10]. The time between defrost cycles or frosting time was determined based on the external air temperature and relative humidity, as expressed in the following Eq. 13.

$$
\triangle t_{d e f}=a_{f r}+b_{f r} \times T_{a}+c_{f r} \times R H+d_{f r} \times T_{a}^{2}+f_{f r} \times R H^{2}+g_{f r} \times T_{a}^{3}+h_{f r} \times R H^{3}
$$


in which $\triangle t_{d e f}$ is the time between defrost cycles or frosting time (min). $T_{a}$ and $R H$ are ambient air temperature $\left({ }^{\circ} \mathrm{C}\right)$ and relative humidity (\%), respectively. $a_{f r}, b_{f r}, c_{f r}, d_{f r}$, $f_{f r}, g_{f r}, h_{f r}$ are empirical coefficients determined from polynomial regression surface. The values and units of these coefficients are detailed in Table 3.

Table 3: Empirical coefficients of frosting function.

\begin{tabular}{lll}
\hline Empirical coefficient & Unit & Value \\
\hline$a_{f r}$ & $\min$ & 39 \\
$b_{f r}$ & $\min /{ }^{\circ} C$ & -1.06 \\
$c_{f r}$ & $\min / \%$ & 0.33 \\
$d_{f r}$ & $\min /{ }^{\circ} C^{2}$ & 0.13 \\
$f_{f r}$ & $\min / \%^{2}$ & -0.0093 \\
$g_{f r}$ & $\min /{ }^{\circ} C^{3}$ & -0.018 \\
$h_{f r}$ & $\min / \%^{3}$ & -0.00006 \\
\hline
\end{tabular}

Duration of a defrost cycle was calculated using Eq. 14. The typical period of a defrost cycle was from one minute to ten minutes according to the monitoring results.

$$
t_{\text {def }}=a_{\text {def }}+b_{\text {def }} \times T_{a}+c_{\text {def }} \times \Delta t_{\text {def }}+d_{\text {def }} \times T_{a}^{2}+f_{\text {def }} \times \Delta t_{\text {def }}^{2}+g_{\text {def }} \times T_{a}^{3}+h_{\text {def }} \times \triangle t_{\text {def }}^{3}
$$

where $t_{d e f}$ is the period of a defrost cycle (min). $\triangle t_{d e f}$ is frosting time $(\min )$, and $T_{a}$ is external air temperature $\left({ }^{\circ} \mathrm{C}\right) . a_{d e f}, b_{d e f}, c_{d e f}, d_{d e f}, f_{d e f}, g_{d e f}, h_{d e f}$ are empirical coefficients obtained from polynomial regression surface. These values are presented in Table 4.

Table 4: Empirical coefficients of defrost function.

\begin{tabular}{lll}
\hline Empirical coefficient & Unit & Value \\
\hline$a_{\text {def }}$ & $\min$ & 56.2 \\
$b_{\text {def }}$ & $\min /{ }^{\circ} \mathrm{C}$ & -0.34 \\
$c_{\text {def }}$ & - & -3.56 \\
$d_{\text {def }}$ & $\min /{ }^{\circ} \mathrm{C}^{2}$ & -0.047 \\
$f_{\text {def }}$ & $1 / \min$ & 0.079 \\
$g_{\text {def }}$ & $\min /{ }^{\circ} \mathrm{C}^{3}$ & 0.0096 \\
$h_{\text {def }}$ & $1 / \mathrm{min}^{2}$ & -0.00057 \\
\hline
\end{tabular}

The proposed cooling energy of a defrost cycle $\left(E_{c, \text { def }}\right)$ (Eq. 15), which is the energy extracted from indoor to outdoor unit to melt the ice accumulation on the evaporator surface, 
and the proposed electric consumption $\left(E_{e, d e f}\right)$ (Eq. 16) during a defrost cycle are defined as follows.

$$
\begin{aligned}
& E_{c, \text { def }}=\frac{t_{d e f} \times Q_{\text {def,mean }}}{60} \\
& E_{e, \text { def }}=\frac{t_{\text {def }} \times W_{\text {def,mean }}}{60}
\end{aligned}
$$

where average cooling capacity during defrost cycles $\left(Q_{\text {def,mean }}\right)$ was obtained from the monitoring results, equalling $1.92 \mathrm{~kW}$. Mean electric input power during defrost cycles $\left(W_{\text {def,mean }}\right)$ was found to be $0.97 \mathrm{~kW}$ from the collected data. These average values were set up in the initial defrost model and calibrated later (as detailed in section 4.1.1).

The TRNSYS simplified defrost model used a modified timer trigger developed by Olivier et al. [49] to counter the frosting time $\Delta t_{\text {def }}$ and defrosting time $t_{d e f}$. Particularly, when the heating signal of the heat pump was on and frost conditions were met, the timer waited for a certain period (frosting time $\Delta t_{d e f}$ ) before activating the defrost signal which forced the heat pump into cooling mode for the specified defrosting time $t_{\text {def }}$.

\subsection{Thermal energy storage model}

TRNSYS Type 534 (TESS library) [43] was used to model the TES. The tank dimensions and characteristics were set up similarly to the field trial TES which is described in section 2.3. The heat loss coefficient of the tank model was calibrated equal $9.9 \mathrm{KJ} / \mathrm{hr} . \mathrm{m}^{2} . \mathrm{K}$.

There was a de-stratification pump mixing water from top to bottom, so a pump model (Type 3d) [36] was also incorporated into the storage tank model.

\subsection{Whole building simulation model}

The heat pump and TES models were integrated into a larger dynamic model containing the building and heat distribution system and DHW, which represents the system shown in Fig. 3.

The building geometry was first drawn in SketchUp software [50] and then imported into TRNSYS Type 56 [36]. The characteristics of the building set up in the model can be seen in Table 5. Boundary profiles obtained from temperature monitoring of adjacent rooms of the adjacent house (House 63 in Fig. 2) was assigned as inputs that affected the internal heat gains of the building model. As occupancy patterns, lights and other electric appliances were not monitored, characteristic internal heat gains regarding weekdays and weekends for the model were developed based on surveys and interviews. 
Table 5: Characteristics of the building set up in the model.

\begin{tabular}{llc}
\hline Parameter & Element & Value \\
\hline Heated area $\left(\mathrm{m}^{3}\right)$ & Ground floor & 110 \\
& First floor & 150 \\
U-value $\left(\mathrm{W} / \mathrm{m}^{2} \mathrm{~K}\right)$ & External wall & 1.65 \\
& Roof & 1.42 \\
& Floor & 0.67 \\
& Window & 4.8 \\
& Garret ceiling & 1.07 \\
& Door & 0.422 \\
Infiltration rate $(\mathrm{ACH})$ & & 1.15 \\
Heat capacitance $(\mathrm{kJ} / \mathrm{K})$ & Ground floor & 2560 \\
& First floor & 2430 \\
\hline
\end{tabular}

The heat distribution system was modelled thoroughly, comprising radiators (Type 1231), valves (Type 11 and Type 647), piping (Type 31), temperature sensors (Type 911) as available in TRNSYS standard [36] and TESS component [43] libraries. During the monitoring sessions, the central heating system was observed to operate mostly between 7am and $11 \mathrm{pm}$ every day maintaining the dining room temperature between $21^{\circ} \mathrm{C}$ and $19.5^{\circ} \mathrm{C}$. Thus, the whole simulation model controlled switching on and off the heating system following this defined schedule and set room temperature.

The DHW tank was modeled using Type 534 [36], containing one immersed heat exchanger with the thermal characteristics the same as the one in the field trial. DHW was charged by the heating system if the top tank temperature was below $50^{\circ} \mathrm{C}$, and it was off when the top tank temperature reached $60^{\circ} \mathrm{C}$. Hot water draw-off patterns in the model were matched to the monitoring data.

\section{Model validation against experimental results}

To validate the models, predictions for the CAWHP performance were compared to the field trial and the laboratory data, with the models' parameters being varied where necessary. The building heat demand of the whole house model was also experimentally verified. 


\subsection{Heat pump model validation}

\subsubsection{Heat pump model calibration and validation based on field trial results}

The heat pump model parameters were finely tuned based on the curves and information informed by the recorded field data, but the initial results of the predicted daily COPs were not highly matched with the measured. It was found that the reference values (reference heat capacity and electric input power in the normalized curves mentioned in section 3.1.3) and the defrost parameters (average cooling capacity and electric power mentioned in section 3.1.4) were the main causes of the model's errors. Therefore, these parameters were calibrated through an optimization of a cost function $(f)$, expressed in Eq. 17, that defines the variation between the measured and simulated daily COPs. GenOpt software [51] in combination with TRNSYS was utilized to automatically alter the calibration parameters to obtain the minimum value of the cost function. Hook-Jeeves algorithm was used for optimization process in GenOpt, which is recommended by Cacabelos et al. [52].

$$
f=C V(R S M E)=\frac{\sqrt{\frac{\sum\left(Y_{\text {sim }}-Y_{\text {measure }}\right)^{2}}{n}}}{\bar{Y}_{\text {measure }}} \times 100
$$

The calibration of the heat pump model was performed utilizing the data collection of the first two monitoring sessions (direct mode and indirect mode). Fig. 7 illustrates the comparison of daily COPs between the calibrated model and monitoring results. Note that the outliers were caused by sensor malfunction. The statistical measures of the calibration results are reported in Table 6. In Table 7, the predicted seasonal COPs of direct mode (2.06) and indirect mode (1.67) highly match with those of the measurement (2.05 for direct mode and 1.63 for indirect mode). It is worth noting that the results in Table 7 are for calibration and validation purpose only. The reference heat capacity and electric input power were calibrated to be $15.1 \mathrm{~kW}$ and $6.9 \mathrm{~kW}$, respectively. The calibrated defrost parameters, including mean cooling capacity and electric power during defrost cycles, were found to be equal to $2.17 \mathrm{~kW}$ and $1.75 \mathrm{~kW}$, respectively. 


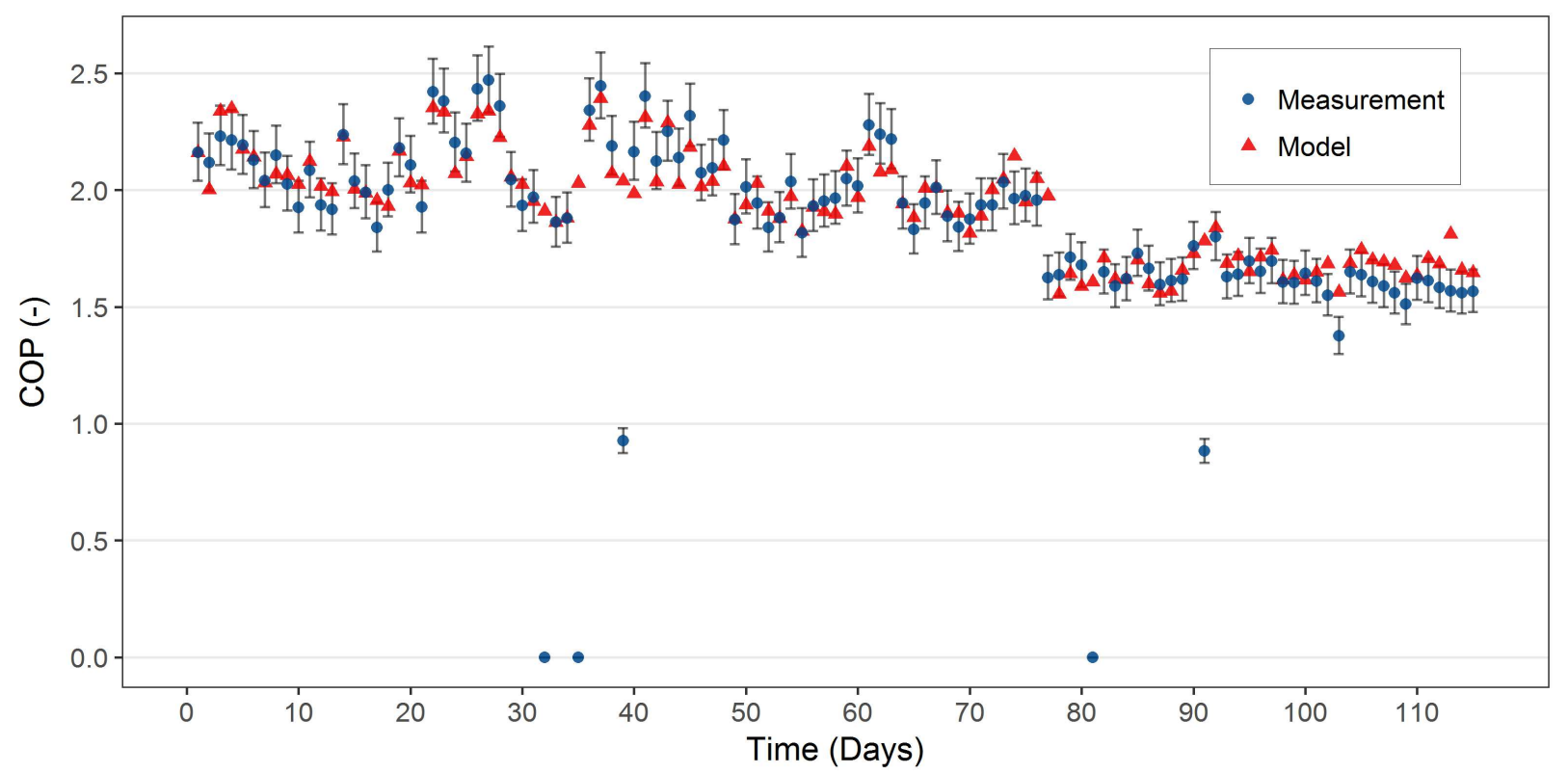

Figure 7: Daily COP comparison between the calibrated model and the measured (direct mode and indirect mode).

Table 6: Statistical measures of the results between the heat pump model and field trial data (the measured values in the days related to sensor fault were removed from the calculations).

\begin{tabular}{lcccccc}
\hline & \multicolumn{2}{c}{ Daily COP } & & \multicolumn{2}{c}{ Daily COP sys } \\
\cline { 2 - 3 } & Calibration & Validation & & Calibration & Validation \\
\hline RMSE [-] & 0.08 & 0.07 & & 0.09 & 0.12 \\
CV(RMSE) [\%] & 4.15 & 3.31 & & 4.88 & 6.03 \\
Maximum Deviation [-] & 0.24 & 0.2 & & -0.19 & -0.34 \\
Percentage of model results in & & & & & 71 & 70 \\
$\pm 5.59 \%$ of measurement uncertainty [\%] & & & & & & \\
\hline
\end{tabular}

Table 7: Seasonal COP comparison between the model's predictions and the field data of three modes (Note that the results in this table are for calibration and validation purpose only).

\begin{tabular}{lcccccc}
\hline & \multicolumn{2}{c}{$\mathrm{COP}$} & & \multicolumn{2}{c}{$\mathrm{COP}_{\text {sys }}$} & \multirow{2}{*}{ Mean $T_{a}\left({ }^{\circ} \mathrm{C}\right)$} \\
\cline { 2 - 3 } & Model & Field trial & & Model & Field trial & \\
\hline Direct Mode & 2.06 & 2.05 & & 2.02 & 2.03 & 4.5 \\
Indirect Mode & 1.67 & 1.63 & & 1.51 & 1.5 & 5.7 \\
Combined Mode & 2.26 & 2.24 & & 1.97 & 1.94 & 9 \\
\hline
\end{tabular}

The validation was carried out on the third monitoring session (combined mode) using the calibrated parameters. It can be seen in Fig. 8 that the simulated daily COPs highly 
coincide with the monitored values, except one outlier of the monitoring due to sensor fault. Maximum daily COP deviation between the results of simulation and measurement was 0.2 , as reported in Table 6. CV(RMSE) and RMSE were $3.31 \%$ and 0.07 , respectively. $88 \%$ of the model's predictions were within the permitted range of the daily COP measurement. In Table 7 , the model predicts a seasonal COP of 2.26 , equivalent to the measured seasonal COP of 2.24 .

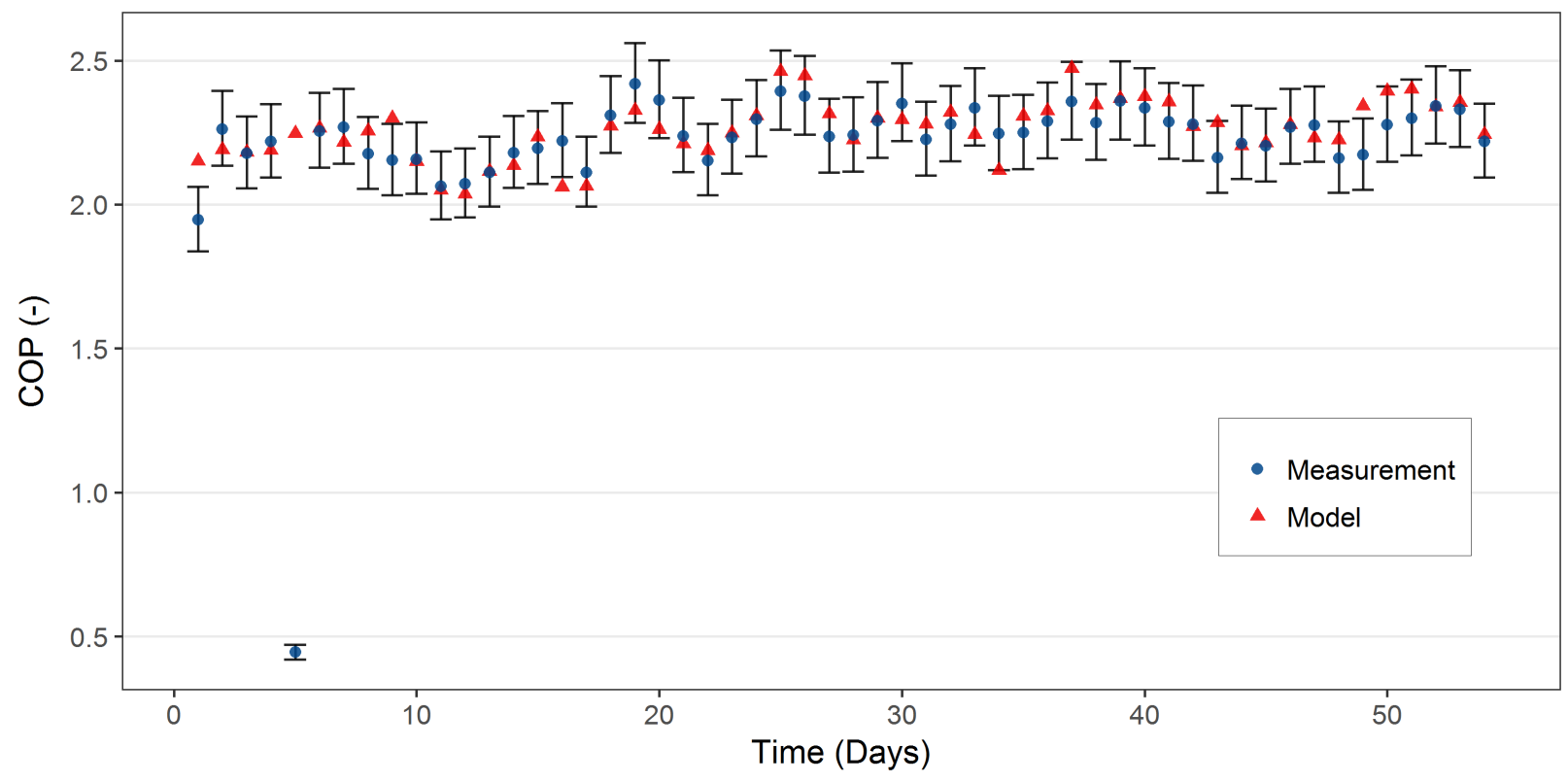

Figure 8: Daily COP comparison between the validated model and the measurement (combined mode).

It is also worthwhile to check the correlation of $\mathrm{COP}_{\text {sys }}$ between the model and the measurement. The comparison of daily $\mathrm{COP}_{\text {sys }}$ for all modes is depicted in Fig. 9. It is noted that the big outliers in the figure are caused by sensor errors. Seasonal $\mathrm{COP}_{\text {sys }}$ are presented in Table 7 in which the predicted efficiency highly matches with the measured. In Table 6, the statistical results of daily $\mathrm{COP}_{\text {sys }}$ are also reported. 


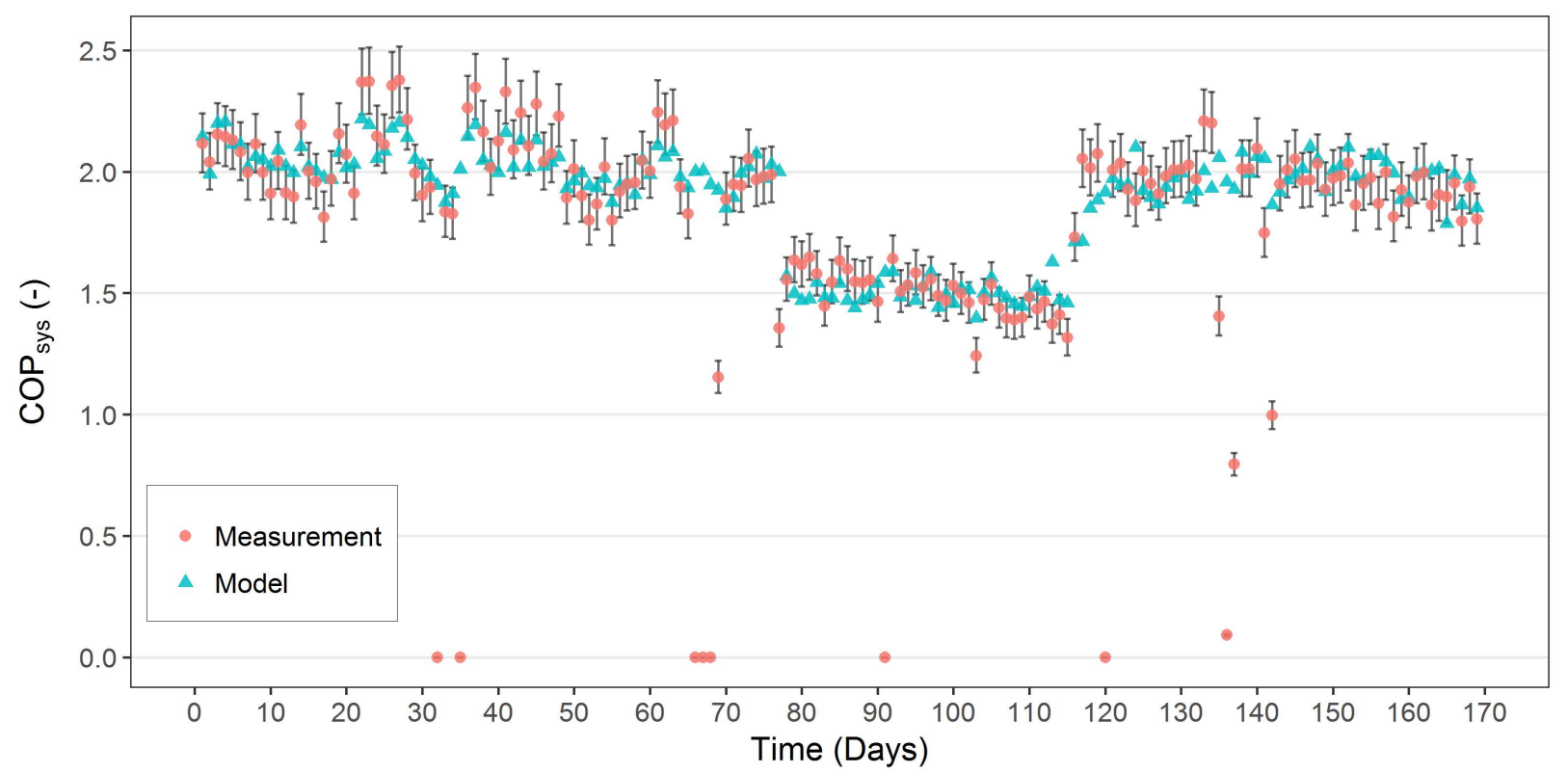

Figure 9: Daily system COP comparison between the model and the measurement for three modes (the big outliers in the figure are of the measurement due to sensor errors).

As mentioned in section 3.1, the model accounted for steady-state only. The transient field trial data is compared to the model in Fig. 10. In the figure, there is an over-shoot during the transient-state of the field heat pump, while this does not happen with the heat pump model. This is because the heat capacity and electric power of the heat pump model were linearly interpolated based on external air temperatures in line with proper outlet water temperatures contained in the performance map, all of which were extracted from the steady-state measured data. After the start-up period (three minutes), the steady-state behaviors of both the model and field heat pump highly match.

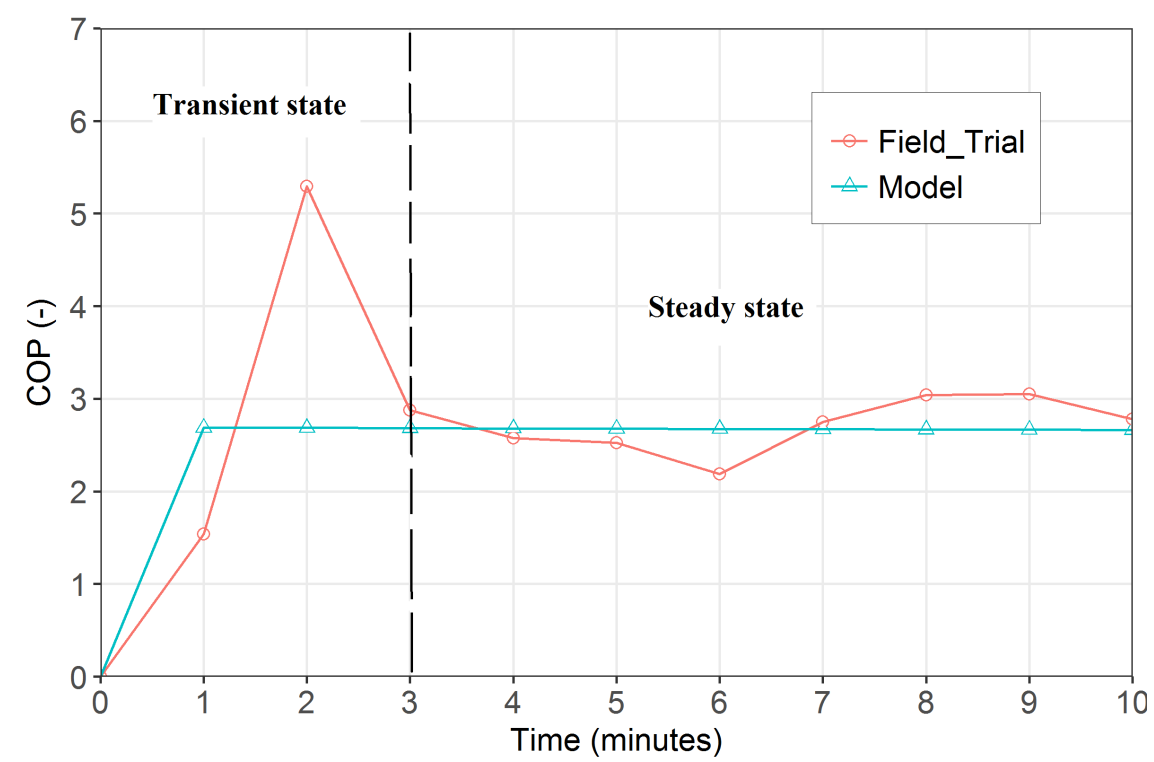

Figure 10: COP transient and steady behaviors between the model and the field trial. 


\subsubsection{Heat pump model validation against laboratory results}

As the heat pump model was developed, calibrated and validated based on the field trial data in which the outdoor air temperatures were not controlled, the reliability of the heat pump model should be checked again. Therefore, the heat pump model's predictions were also compared with the data obtained from the laboratory experiments. Fig. 11 shows the comparison results between the heat pump model and laboratory experiments. The predicted electric power is within the uncertainty range of $\pm 1.5 \%$ (Fig. 11a), and the COP computed from the model is also within the difference of $\pm 5.59 \%$ (Fig. 11b).

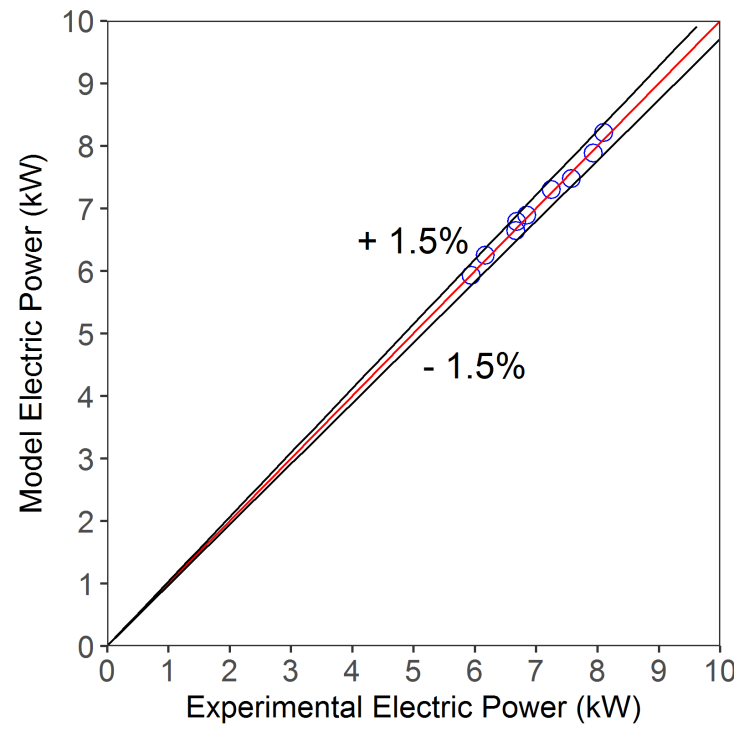

(a) Electric power comparison.



(b) COP comparison.

Figure 11: Comparison between the heat pump model and laboratory experimental results.

\subsection{Building model validation}

Fig. 12 depicts daily heat demand comparison between the house model and the field trial over three periods. The curve depicting monitored daily building heat demand with regards to daily mean ambient temperature was also compared with the one illustrating simulated daily building heat demand versus daily mean outdoor temperature (Fig. 13), following the approach proposed by Safa et al. [53] [54]. In Fig. 13, the relationship between daily heat demand versus ambient temperature of the model's predictions highly coincides with that of the field data according to the linear regressions. Note that the outliers caused by sensor malfunction in Fig. 12 were removed in Fig. 13. As a result, RMSE and CV(RMSE) were calculated to be 16.39 and $18.14 \%$, respectively. 


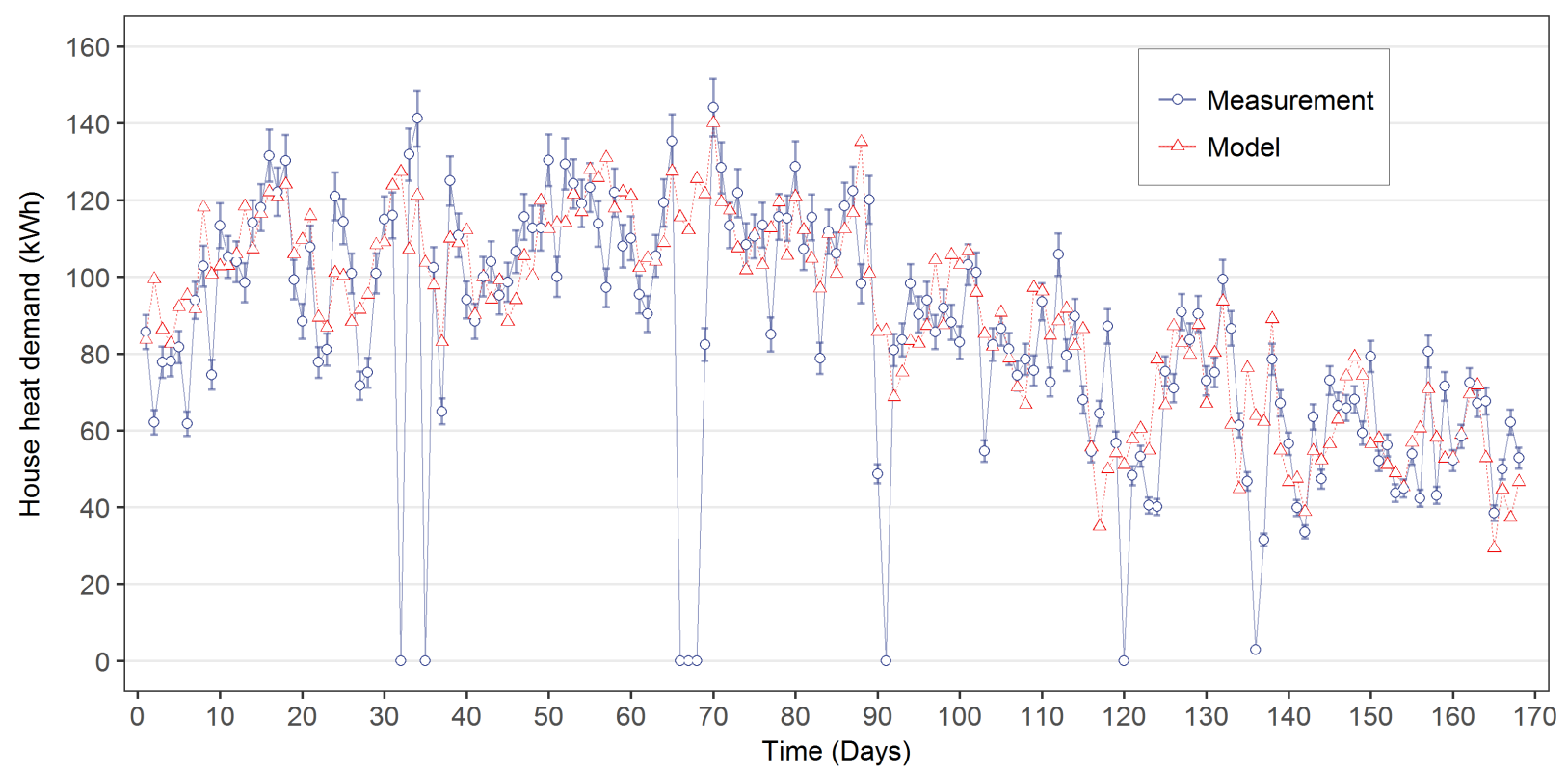

Figure 12: Daily building heat demand comparison between the model and the field data for three periods.

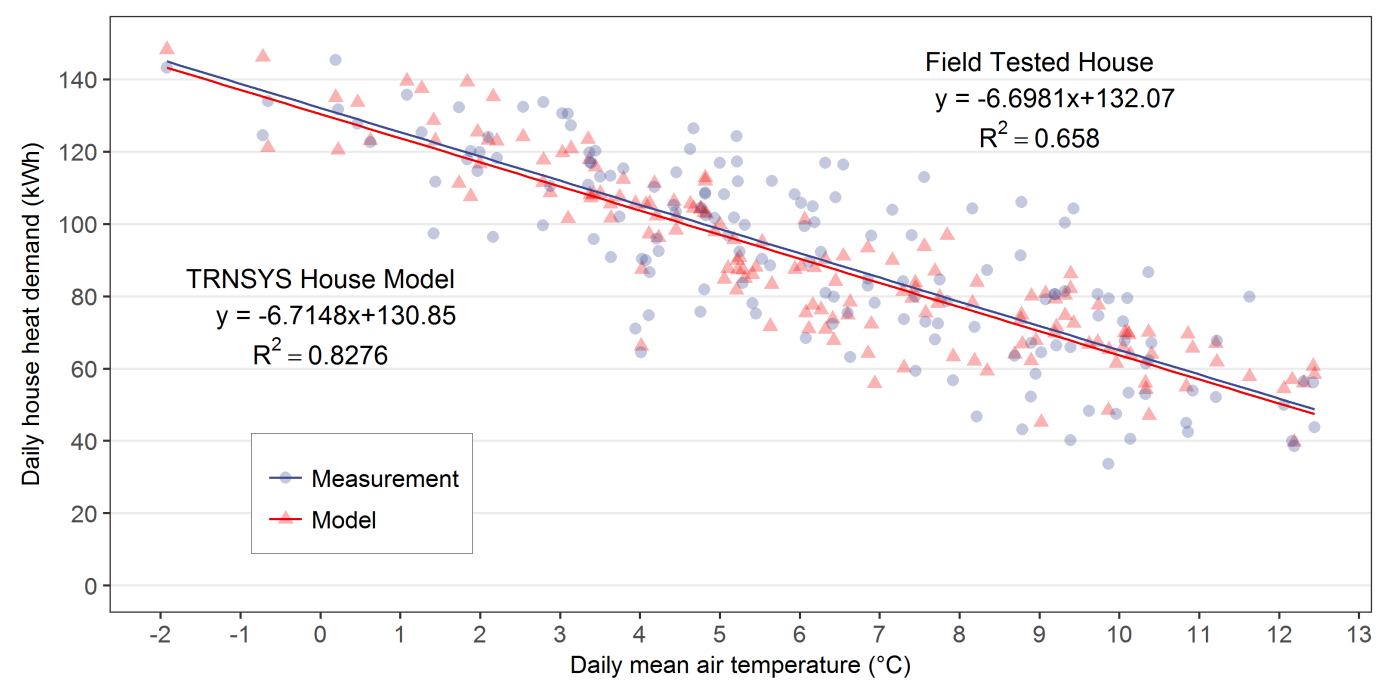

Figure 13: Daily house heat demand versus daily mean air temperature between the model and the field.

\section{Simulations}

After developing and validating the models, the whole dynamic building simulation model was run with one-minute intervals in order to capture operation of the system at high resolutions. Two main series of simulations were performed, including annual simulations for the CAWHP system with and without the TES, as explained in the following sections.

\subsection{Annual simulations of the stand-alone CAWHP system}

In this step, the system of the stand-alone CAWHP (without TES) was extracted for annual predictions. There were two main purposes of these simulations. The first was to 
assess the technical and economic performances of the stand-alone CAWHP when retrofitted into a typical house in Belfast, Northern Ireland and other locations across the UK. Another goal was to evaluate the performance enhancement of the heat pump when it adopted weather compensation strategy.

Firstly, a set of annual simulations was run with different climatic conditions, including Belfast, Aviemore, Camborne and Bracknell. Geography of the selected locations can be seen in Fig. 14. These locations range from northern Scotland to southern England, which represent the variations from severe to mild weather in the UK. Meteonorm weather profiles available in TRNSYS database were used to run the simulations. In Table 8, heating degree days (HDDs) along with the maximum and minimum hourly average external air temperatures are reported to indicate the heat demands in the selected locations. HDDs were computed based on the chosen weather files in TRNSYS with the base temperature of $15.5^{\circ} \mathrm{C}$, the standard in the UK [55]. The outlet water temperature of the heat pump was fixed to $75^{\circ} \mathrm{C}$ for all simulations, which is the same as the field trial.

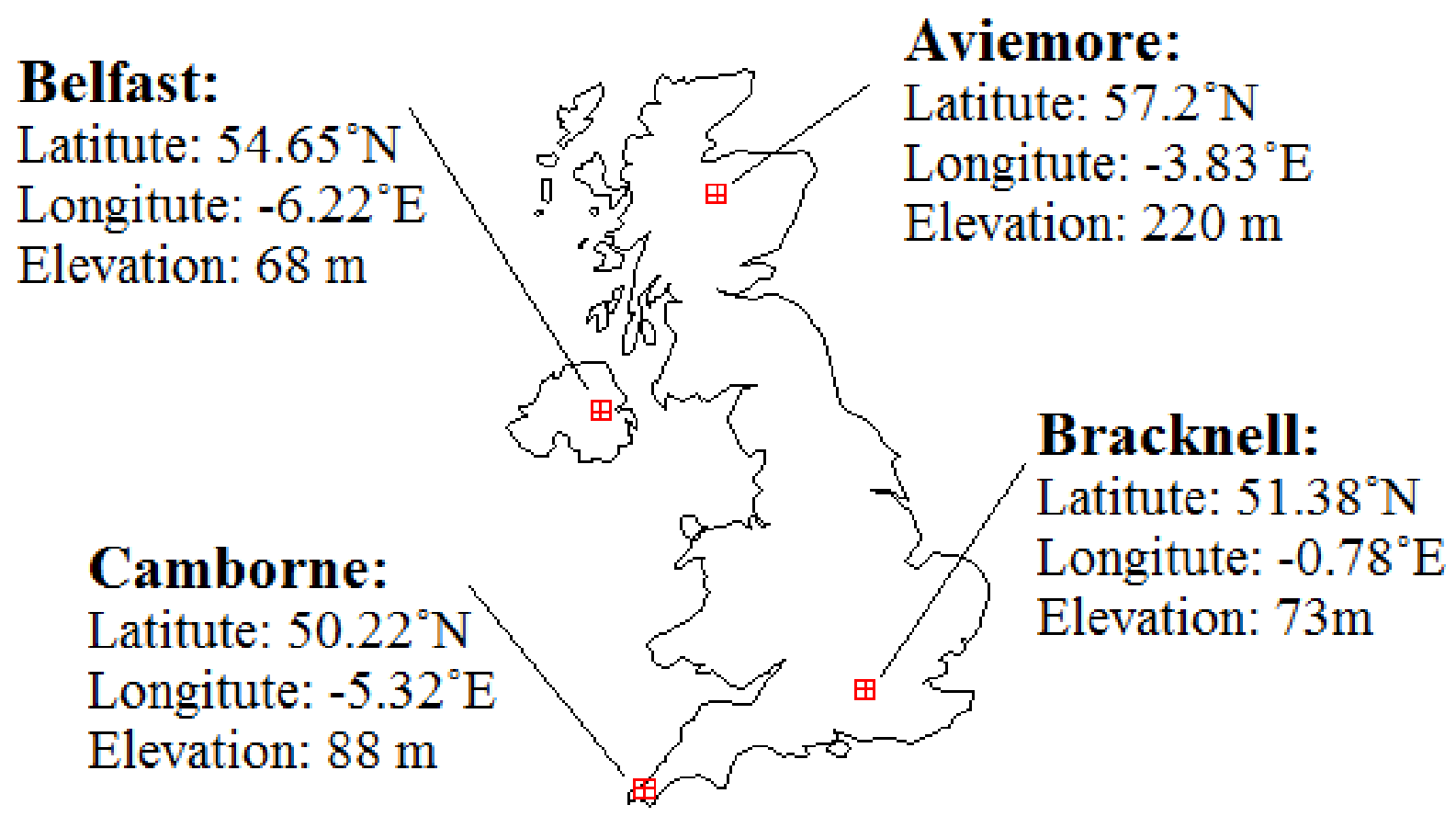

Figure 14: The UK selected locations carried out in the simulations.

Secondly, another set of annual simulations was done in the manner that weather compensation control was employed for the heat pump. The minimum outlet water temperature was set to $65^{\circ} \mathrm{C}$ if the external air temperature was $15^{\circ} \mathrm{C}$ and above, while the maximum outlet was set to $75^{\circ} \mathrm{C}$ corresponding to the ambient temperature of $0^{\circ} \mathrm{C}$ and below (Fig. 15). This simulation set was carried out for all four climate profiles. 


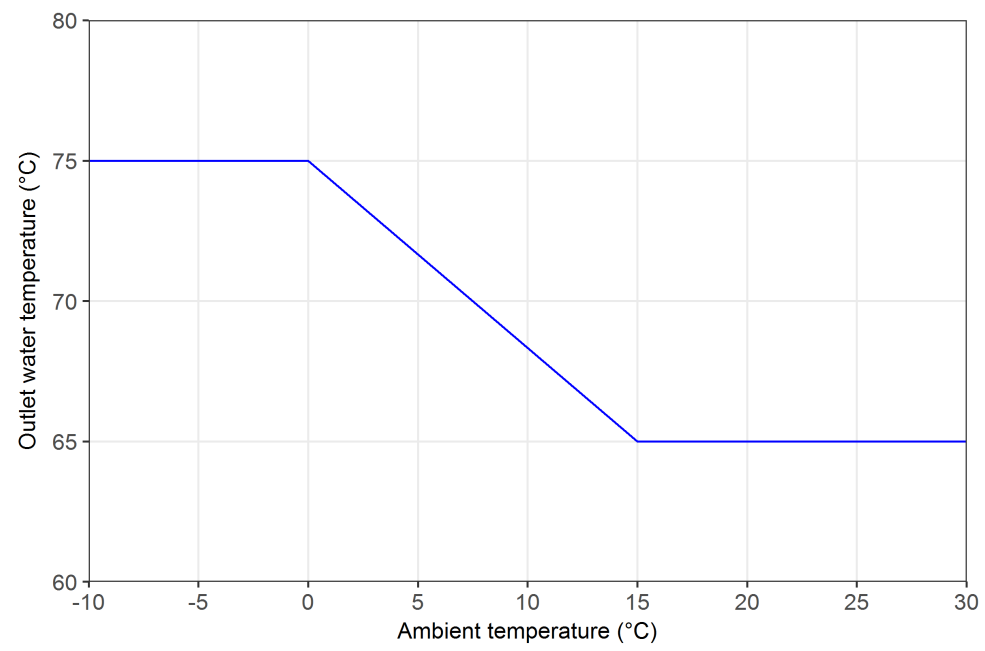

Figure 15: Outlet water temperature versus ambient temperature for weather compensation strategy set-up.

Table 8: Heating degree days and hourly air temperature ranges of the selected locations.

\begin{tabular}{lccc}
\hline Location & HDD & Hourly max. air temperature $\left[{ }^{\circ} \mathrm{C}\right]$ & Hourly min. air temperature $\left[{ }^{\circ} \mathrm{C}\right]$ \\
\hline Belfast & 2475 & 23.8 & -5.6 \\
Aviemore & 3203 & 24.3 & -11.2 \\
Camborne & 1840 & 23.7 & -4.09 \\
Bracknell & 2092 & 29.5 & -6.2 \\
\hline
\end{tabular}

\subsection{Annual simulations of the CAWHP coupled with the TES}

To assess the performance of the system of CAWHP coupled with the TES in terms of different configurations, along with the annual simulation of the direct mode (standalone system) in Belfast mentioned previously, two more simulations regarding the buffering system (indirect mode) and the load-shifting (combined mode) were investigated with the same weather file (Belfast). Other boundary conditions (e.g. internal heat gains) were kept similar for all simulations, allowing the extracted annual results to be equally compared. It is noted that these simulations were limited to the heat pump with fixed flow temperature, while weather compensation was not investigated.

\section{Simulation results and discussion}

\subsection{Stand-alone CAWHP system (without TES)}

\subsubsection{Stand-alone CAWHP system in Northern Ireland}

The predicted performance of the stand-alone CAWHP with and without weather compensation in Belfast, Northern Ireland are summarized in Table 9, with summer months 
(June to August) consisting of DHW demands only. With regards to the fixed outlet water temperature, the annual heat delivered was approximately 89.96 GJ (24989 kWh), and the yearly electric consumption accounted for 42.39 GJ $(11777 \mathrm{kWh})$. The annual COP $\mathrm{Cys}_{\text {s }}$ thus turned out to be 2.12 , with the monthly $\mathrm{COP}_{\text {sys }}$ ranging from 1.98 to 2.54 and the average $\mathrm{COP}_{\text {sys }}$ of the winter period (December to March) equalling 2.02.

Table 9: Summary of annual simulation results of the stand-alone CAWHP system in Belfast-Northern Ireland.

\begin{tabular}{lccccccccccccc}
\hline & Jan & Feb & Mar & Apr & May & Jun & Jul & Aug & Sep & Oct & Nov & Dec & Annual \\
\hline Air temperature $\left[{ }^{\circ} \mathrm{C}\right]$ & 3.6 & 3.9 & 5.5 & 7.3 & 10.2 & 13 & 14.7 & 14.5 & 12.2 & 9.9 & 5.9 & 4.7 & $\mathbf{8 . 8}$ \\
a) Fixed outlet water temperature & $\left(\mathbf{7 5} \mathbf{~}^{\circ} \mathbf{C}\right)$ & & & & & & & & & \\
COP $_{\text {sys }}[-]$ & 1.98 & 2.00 & 2.07 & 2.17 & 2.31 & 2.44 & 2.54 & 2.51 & 2.42 & 2.29 & 2.10 & 2.04 & $\mathbf{2 . 1 2}$ \\
Electric use $[\mathrm{kWh}]$ & 1808 & 1615 & 1459 & 1062 & 734 & 139 & 115 & 134 & 624 & 953 & 1448 & 1686 & $\mathbf{1 1 7 7 7}$ \\
Heat output $[\mathrm{kWh}]$ & 3588 & 3230 & 3025 & 2308 & 1697 & 339 & 291 & 337 & 1513 & 2186 & 3040 & 3435 & $\mathbf{2 4 9 8 9}$ \\
b) Weather $\mathbf{c o m p e n s a t i o n}$ & & & & & & & & & & & & \\
COP sys $[-]$ & 2.09 & 2.12 & 2.24 & 2.43 & 2.66 & 3.02 & 3.14 & 3.11 & 2.85 & 2.62 & 2.27 & 2.17 & $\mathbf{2 . 3 2}$ \\
Electric use $[\mathrm{kWh}]$ & 1675 & 1500 & 1312 & 911 & 607 & 109 & 89 & 107 & 505 & 793 & 1300 & 1552 & $\mathbf{1 0 4 6 0}$ \\
Heat output $[\mathrm{kWh}]$ & 3504 & 3177 & 2940 & 2213 & 1613 & 328 & 280 & 332 & 1439 & 2075 & 2951 & 3362 & $\mathbf{2 4 2 1 6}$ \\
\hline
\end{tabular}

Regarding the heat pump adopted weather compensation strategy, the annual $\mathrm{COP}_{\text {sys }}$ was about 9.4\% higher than the one with fixed outlet water temperature (Table 9). This resulted in approximately $11.2 \%$ of annual energy savings being achieved with the weather compensation strategy. The details of the monthly $\mathrm{COP}_{\text {sys }}$ improvements, indicating the enhancement of the heat pump when adopted weather compensation compared to fixed outlet water temperature, can be seen in Fig. 16. The higher mean air temperatures corresponded to the higher monthly $\mathrm{COP}_{\text {sys }}$ enhancements, and vice versa. The monthly $\mathrm{COP}_{\text {sys }}$ enhancements ranged from approximately $5.4 \%$ to $23.9 \%$, with the highest in summer period and the lowest in winter months. 


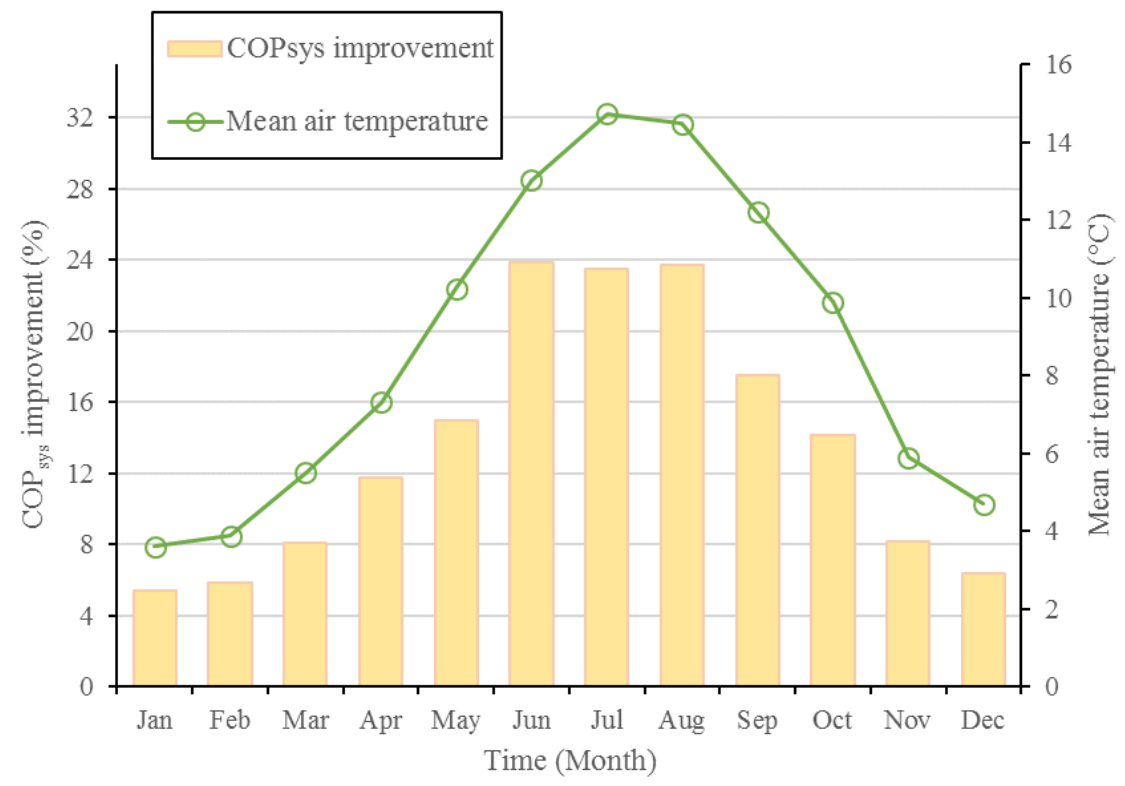

Figure 16: Influence of weather compensation on monthly $\mathrm{COP}_{\text {sys }}$ improvements in Belfast-Northern Ireland.

\subsubsection{Stand-alone CAWHP system in different locations}

The annual $\mathrm{COP}_{\text {sys }}$ of the heat pump primarily depended on weather conditions. In Table 10, as for the fixed outlet water temperature, the CAWHP had the best performance in Camborne (yearly $\mathrm{COP}_{\text {sys }}$ of 2.24) thanks to the mildest weather condition (HDDs of 1840 reported in Table 8) compared to the other locations. In contrast, the heat pump had the lowest performance in Aviemore (annual $\mathrm{COP}_{\text {sys }}$ of 2.03) due to the extreme weather condition where the external air temperature dropped to $-11.2^{\circ} \mathrm{C}$ along with the highest HDDs of 3203 (Table 8). The heat pump's performances in Bracknell and Belfast were better than the one in Aviemore but worse than that in Camborne, with annual $\mathrm{COP}_{\text {sys }}$ of 2.17 and 2.12 , respectively. Regarding the heat pump with weather compensation, the yearly $\mathrm{COP}_{\text {sys }}$ also ranged from the highest (2.5) in milder condition Camborne to the lowest (2.17) in severe condition Aviemore. These yearly figures indicate that the retrofit CAWHP is unlikely to be suitable for renewable heat incentive (RHI) scheme in the UK requiring a seasonal performance factor of 2.5 [56]. 
Table 10: Annual simulation results of the stand-alone CAWHP in different climates.

\begin{tabular}{lcccccccc}
\hline Location & \multicolumn{2}{c}{ Fixed outlet water temperature $\left(75^{\circ} \mathrm{C}\right)$} & & \multicolumn{3}{c}{ Weather compensation } \\
\cline { 2 - 3 } \cline { 7 - 8 } & Yearly & Total electric & Total delivered & & Yearly & Total electric & Total delivered \\
& COP $_{\text {sys }}[-]$ & use $[\mathrm{kWh}]$ & heat $[\mathrm{kWh}]$ & & COP $_{\text {sys }}[-]$ & use $[\mathrm{kWh}]$ & heat $[\mathrm{kWh}]$ \\
\hline Belfast & 2.12 & 11777 & 24989 & & 2.32 & 10460 & 24216 \\
Aviemore & 2.03 & 13962 & 28396 & & 2.17 & 12728 & 27615 \\
Camborne & 2.24 & 9427 & 21100 & & 2.5 & 8105 & 20299 \\
Bracknell & 2.17 & 10740 & 23335 & & 2.38 & 9321 & 22144 \\
\hline
\end{tabular}

The employment of weather compensation strategy permitted the retrofit CAWHP to perform at a higher COP. Milder weather conditions can allow this strategy to improve the heat pump's performances further. To better explain this effect, Fig. 17 illustrates the relationship between the annual $\mathrm{COP}_{\text {sys }}$ enhancement and the weighted mean of hourly ambient temperature $\left(T_{w m a}\right)$ in different locations, following the approach proposed by Madonna and Bazzocchi [10]. The improvement of yearly $\mathrm{COP}_{\text {sys }}$ changed relatively according to the climatic variations. In particular, it was approximately $6.7 \%$ in Aviemore $\left(T_{w m a}\right.$ of $\left.6^{\circ} \mathrm{C}\right), 9.1 \%$ in Belfast $\left(T_{w m a}\right.$ of $\left.8.4^{\circ} \mathrm{C}\right), 9.3 \%$ in Bracknell $\left(T_{w m a}\right.$ of $\left.10.2^{\circ} \mathrm{C}\right)$ and $11.9 \%$ in Camborne $\left(T_{w m a}\right.$ of $\left.10.6{ }^{\circ} \mathrm{C}\right)$.

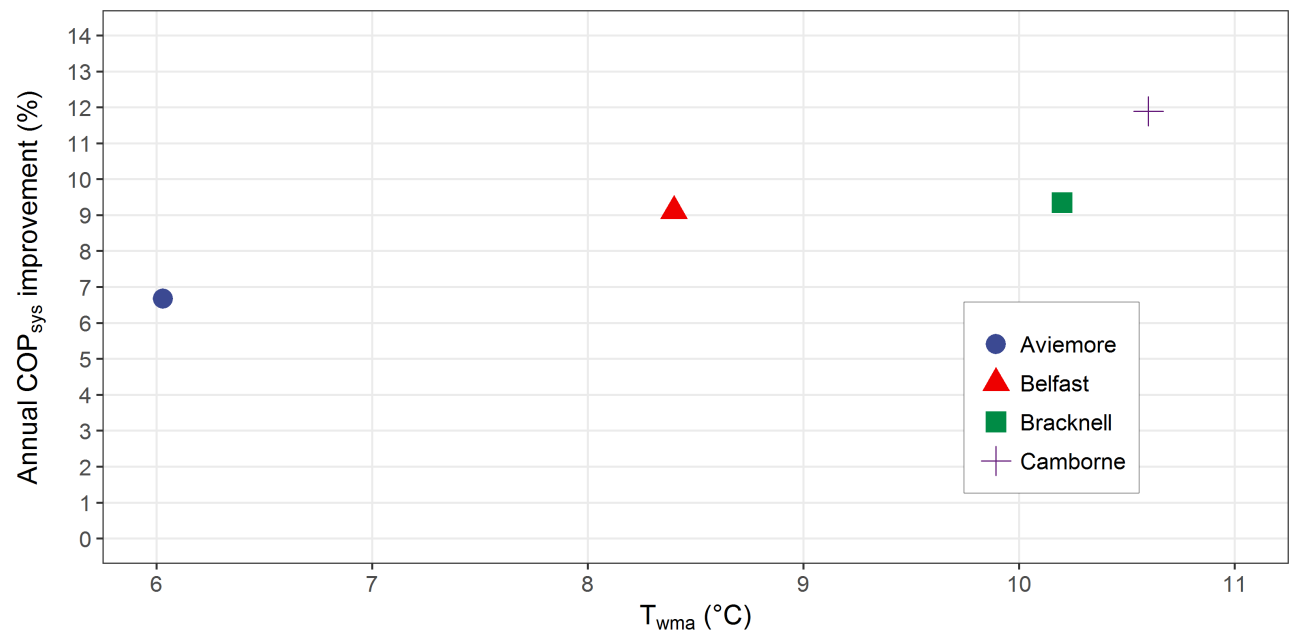

Figure 17: Influence of weather compensation on annual $\mathrm{COP}_{s y s}$ improvements as a function of $T_{w m a}$.

With the annual electric consumption predicted in all locations, the annual costs for running the retrofit CAWHP were calculated based on the electricity price of $£ 0.175 / \mathrm{kWh}$ observed in November 2018 [57], as reported in Table 11. As expected, the heat pump operating in Camborne accounted for the lowest running cost (£1650 for the fixed outlet temperature and $£ 1418$ for the weather compensation), whereas there was a running cost 
penalty in the other locations, with the most expensive running cost in Aviemore (£2443 for the fixed outlet temperature and $£ 2227$ for the weather compensation).

Table 11: Annual results of energy consumption, running costs and carbon emissions of the stand-alone retrofit CAWHP and gas and oil boilers.

Belfast Aviemore Bracknell Camborne

1) Retrofit CAWHP

a) Fixed outlet water temperature $\left(75^{\circ} \mathrm{C}\right)$

$\begin{array}{lllll}\text { Annual electric use }[\mathrm{kWh}] & 11777 & 13962 & 10740 & 9427\end{array}$

Annual running cost $[£] \quad 2061 \quad 2443 \quad 1880 \quad 1650$

Annual $\mathrm{CO}_{2}$ emissions [kg] $4527 \quad 5367 \quad 4129 \quad 3624$

b) Weather compensation control

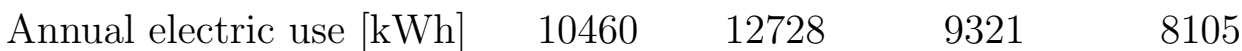

$\begin{array}{lllll}\text { Annual running cost }[£] & 1831 & 2227 & 1631 & 1418\end{array}$

Annual $\mathrm{CO}_{2}$ emissions [kg] $4021 \quad 4893 \quad 3583 \quad 3116$

2) Oil boiler

a) $60 \%$ efficiency

Annual oil use [kWh] $\quad 34895 \quad 39754 \quad 32669 \quad 29540$

$\begin{array}{llll}\text { Annual running cost }[£] & 2379 & 2703 & 2221\end{array}$

Annual $\mathrm{CO}_{2}$ emissions [kg] $\quad 8501 \quad 9660 \quad 7939 \quad 7178$

b) $70 \%$ efficiency

$\begin{array}{lllll}\text { Annual oil use }[\mathrm{kWh}] & 32486 & 36915 & 30336 & 27430\end{array}$

Annual running cost $[£] \quad 2209 \quad 2510 \quad 2063 \quad 1865$

Annual $\mathrm{CO}_{2}$ emissions [kg] $7894 \quad 8970 \quad 7372 \quad 6665$

c) $80 \%$ efficiency

$\begin{array}{lllll}\text { Annual oil use }[\mathrm{kWh}] & 29987 & 34075 & 28002 & 25320\end{array}$

$\begin{array}{lllll}\text { Annual running cost }[£] & 2039 & 2317 & 1904 & 1722\end{array}$

Annual $\mathrm{CO}_{2}$ emissions [kg] $\quad 7287 \quad 8280 \quad 6804 \quad 6153$

d) $90 \%$ efficiency

$\begin{array}{lllll}\text { Annual oil use }[\mathrm{kWh}] & 27488 & 31236 & 25669 & 23210\end{array}$

$\begin{array}{lllll}\text { Annual running cost }[£] & 1869 & 2124 & 1745 & 1578\end{array}$

Annual $\mathrm{CO}_{2}$ emissions [kg] $6680 \quad 7590 \quad 6237 \quad 5640$

3) Gas boiler

a) $60 \%$ efficiency

$\begin{array}{lllll}\text { Annual gas use }[\mathrm{kWh}] & 34895 & 39754 & 32669 & 29540\end{array}$ 


\begin{tabular}{lcccc} 
Annual running cost [£] & 1646 & 1865 & 1539 & 1396 \\
Annual $\mathrm{CO}_{2}$ emissions [kg] & 6997 & 7951 & 6534 & 5908 \\
b) $\mathbf{7 0 \%}$ efficiency & & & & \\
Annual gas use [kWh] & 32486 & 36915 & 30336 & 27430 \\
Annual running cost [£] & 1531 & 1734 & 1432 & 1299 \\
Annual $\mathrm{CO}_{2}$ emissions [kg] & 6497 & 7383 & 6067 & 5486 \\
c) $\mathbf{8 0 \%}$ efficiency & & & & \\
Annual gas use [kWh] & 29987 & 34075 & 28002 & 25320 \\
Annual running cost [£] & 1416 & 1604 & 1325 & 1202 \\
Annual $\mathrm{CO}_{2}$ emissions $[\mathrm{kg}]$ & 5997 & 6815 & 5600 & 5064 \\
d) $\mathbf{9 0 \%}$ efficiency & & & & \\
Annual gas use [kWh] & 27488 & 31236 & 25669 & 23210 \\
Annual running cost [£] & 1301 & 1474 & 1218 & 1105 \\
Annual $\mathrm{CO}_{2}$ emissions $[\mathrm{kg}]$ & 5498 & 6247 & 5134 & 4642 \\
\hline
\end{tabular}

Similar to the running cost calculations, annual carbon emissions were estimated based on the yearly simulated electric use figures. Carbon conversion factor for grid electricity was $0.3844 \mathrm{kgCO} / \mathrm{kWh}$, including electricity generation and transmission and distribution factors [58]. In Table 11, the CAWHP with fixed flow temperature emitted the annual carbon dioxide of $3624 \mathrm{~kg}, 4129 \mathrm{~kg}, 4527 \mathrm{~kg}$ and $5367 \mathrm{~kg}$ in Camborne, Bracknell, Belfast and Aviemore, respectively. With weather compensation, carbon emissions in Camborne could be reduced up to $14 \%$, while $8.83 \%$ of carbon savings could be obtained in Aviemore.

\subsubsection{Retrofit assessment of the stand-alone CAWHP system}

To assess the retrofit performance of the selected CAWHP, the results of gas and oil boilers with $60 \%, 70 \%, 80 \%$ and $90 \%$ efficiency, representing from old heavy weight boilers to new condensing boilers which are popular in the UK housing stock, are also reported in Table 11 for comparison purpose. The oil price per kWh was $£ 0.068$ [59]. The gas price was $£ 0.06508 / \mathrm{kWh}$ for the first $2000 \mathrm{kWh}$, and $£ 0.0459 / \mathrm{kWh}$ for the after $2000 \mathrm{kWh}[60]$. The carbon emissions factors were $0.2 \mathrm{kgCO} / \mathrm{kWh}$ for gas and $0.243 \mathrm{kgCO} / \mathrm{kWh}$ for oil [58].

Fig. 18 shows the percentage of running cost savings of gas and oil boilers compared to the CAWHP. Positive values in the figures indicate that the heat pump running costs were lower, while negative values indicate the heat pumps were more expensive to operate. Considering the fixed flow water temperature heat pump, the selected CAWHP had higher running costs than the gas boilers and $90 \%$ efficiency oil boiler in all locations as well as $80 \%$ 
efficiency oil boiler in Aviemore and Belfast (Fig. 18a). There were cost savings (between $3 \%$ and $18 \%$ ) if the oil boilers at $60 \%$ and $70 \%$ efficiencies were replaced by the selected CAWHP. Regarding the CAWHP with weather compensation control, running the retrofit heat pump was more expensive than operating the gas boilers in all locations and $90 \%$ efficiency oil boiler in Aviemore (Fig. 18b). However, cost savings (from 4\% to 29\%) could be obtained if the oil boilers were retrofitted by the CAWHP (except $90 \%$ efficiency oil boiler in Aviemore). In short, these results indicate that there is a barrier for this CAWHP to be retrofitted into the dwellings currently using gas boilers, but there are cost benefits if the heat pump replaces the low-efficiency oil boilers.

Apart from the running costs reported above, the heat pump capital costs are provided to give a broader view of CAWHP as a retrofit heating technology. As CAWHP products that can provide high flow water temperatures are not widely accepted in the UK market, the product costs are high, ranging from about $£ 5900$ to $£ 7900$ with respect to product capacity ranges of $11 \mathrm{~kW}$ and $16 \mathrm{~kW}$ [61] [62]. The installation costs were from $£ 3000$ to $£ 4000$ [31]. As a result, the capital costs turn out to be $£ 8900$ - 11900 . If a TES tank is needed, an extra cost of $£ 900$ - 2000 (including product itself and accessories) is added to the capital costs.

With regards to carbon emissions, the retrofit CAWHP could attain relative carbon reductions (from $14 \%$ to $57 \%$ ) compared to the figures of gas and oil boilers (Fig. 19). In the future, the UK electricity grid will have higher proportions of renewable energy generation, thus making the retrofit heat pump even more competitive with fossil-fueled boilers in terms of the UK's aim to achieve binding carbon emissions reduction targets. 


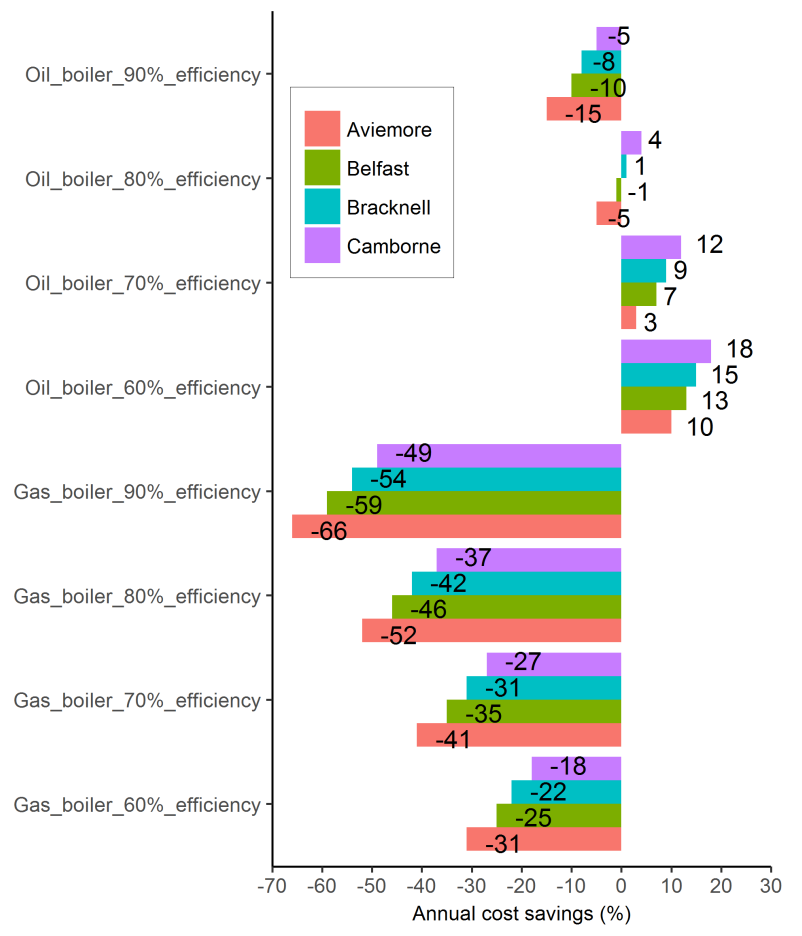

a. Fixed flow CAWHP compared with boilers

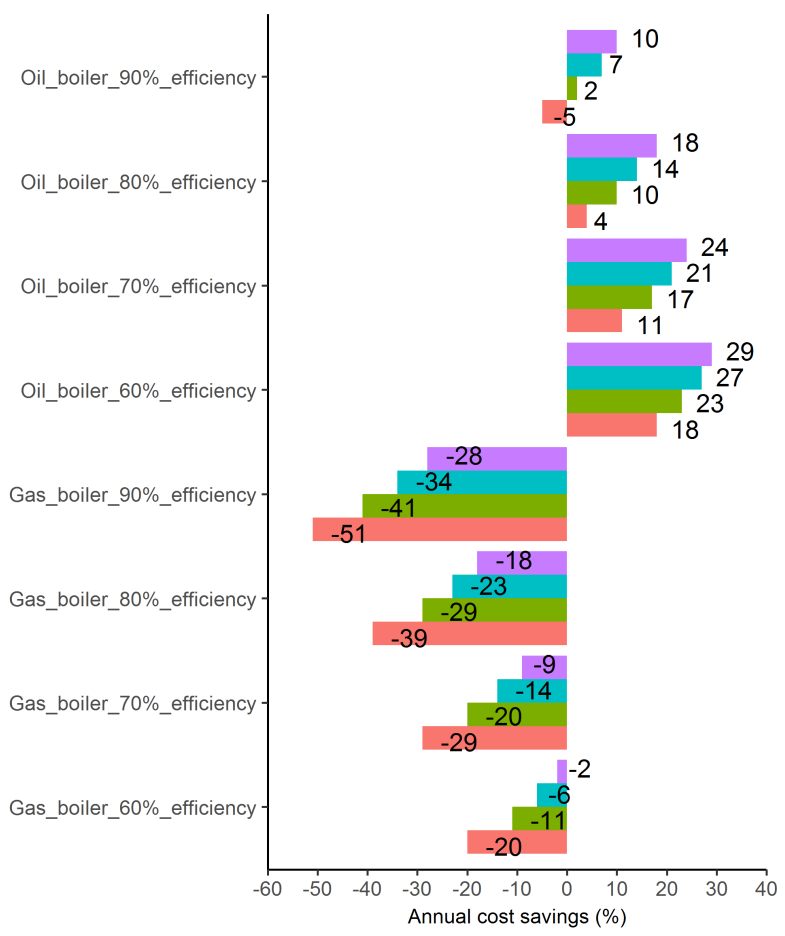

b. Weather compensation CAWHP compared with boilers

Figure 18: Annual operating cost savings of the retrofit CAWHP compared with boilers (positive values in the figure indicate the heat pump running costs are lower compared to boilers, while negative values indicate the heat pump operating costs are higher than those of boilers).
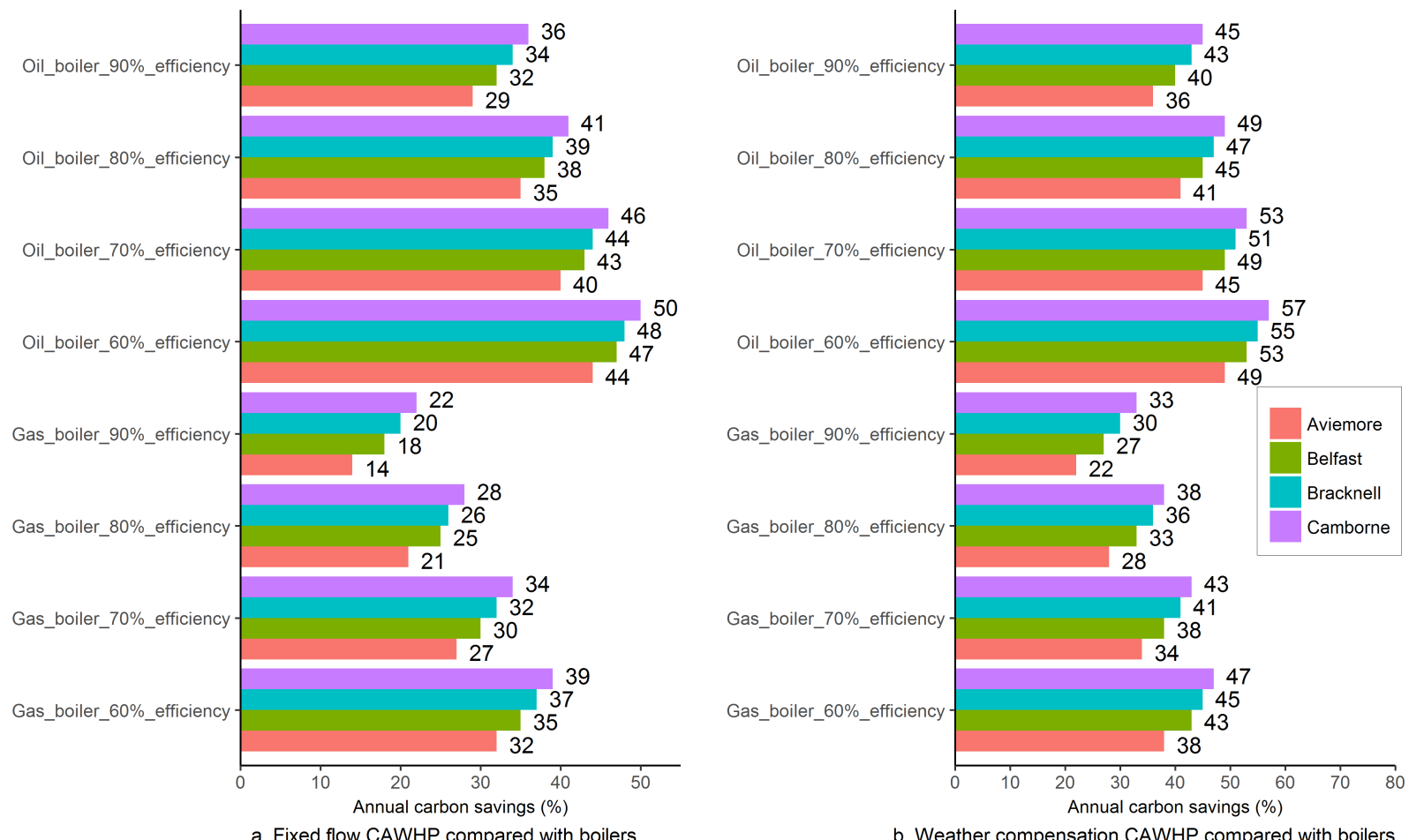

b. Weather compensation CAWHP compared with boilers

Figure 19: Annual carbon emissions savings of the retrofit CAWHP compared with boilers (positive values in the figure indicate the carbon emissions of the heat pump are lower than those of the boilers). 


\subsection{CAWHP coupled with TES system}

For comparison between the direct mode and the buffering system, the direct mode had a higher yearly COP than the buffering, as reported in Table 12. The heat pump in the buffering system produced higher flow temperatures, approximately $4^{\circ} \mathrm{C}$ higher than the outlet temperature of the heat pump in direct mode $\left(75^{\circ} \mathrm{C}\right)$ (Fig. 20a and 20b). This is because the temperature at which heat is provided to the storage via a heat exchanger needs to be higher to top up the tank, and this behavior was also mentioned for the integrated system of a single-stage AWHP and TES by Kelly et al. [63]. This higher flow temperature led to the lower COP of the buffering system. Additionally, due to the parasitic losses of the storage tank, the buffering system yielded a yearly $\mathrm{COP}_{\text {sys }}$ of 1.41 , which was about $33 \%$ lower efficiency compared to direct heating (Table 12).

Table 12: Simulation results of three mode operations.

\begin{tabular}{lccc}
\hline & Direct Mode & Indirect Mode & Combined Mode \\
\hline Annual COP [-] & 2.14 & 1.66 & 2.11 \\
Annual COP sys $[-]$ & 2.12 & 1.41 & 1.88 \\
Annual electric use $[\mathrm{kWh}]$ & 11777 & 17304 & 13296 (Day: $10045 ;$ Night: 3251 ) \\
Annual useful heat $[\mathrm{kWh}]$ & 24989 & 24343 & 24964 \\
Average room temperature $\left[{ }^{\circ} \mathrm{C}\right]$ & 19.7 & 19.6 & 19.8 \\
Annual operating costs $[£]$ & 2061 & 3028 & 1976 \\
\hline
\end{tabular}




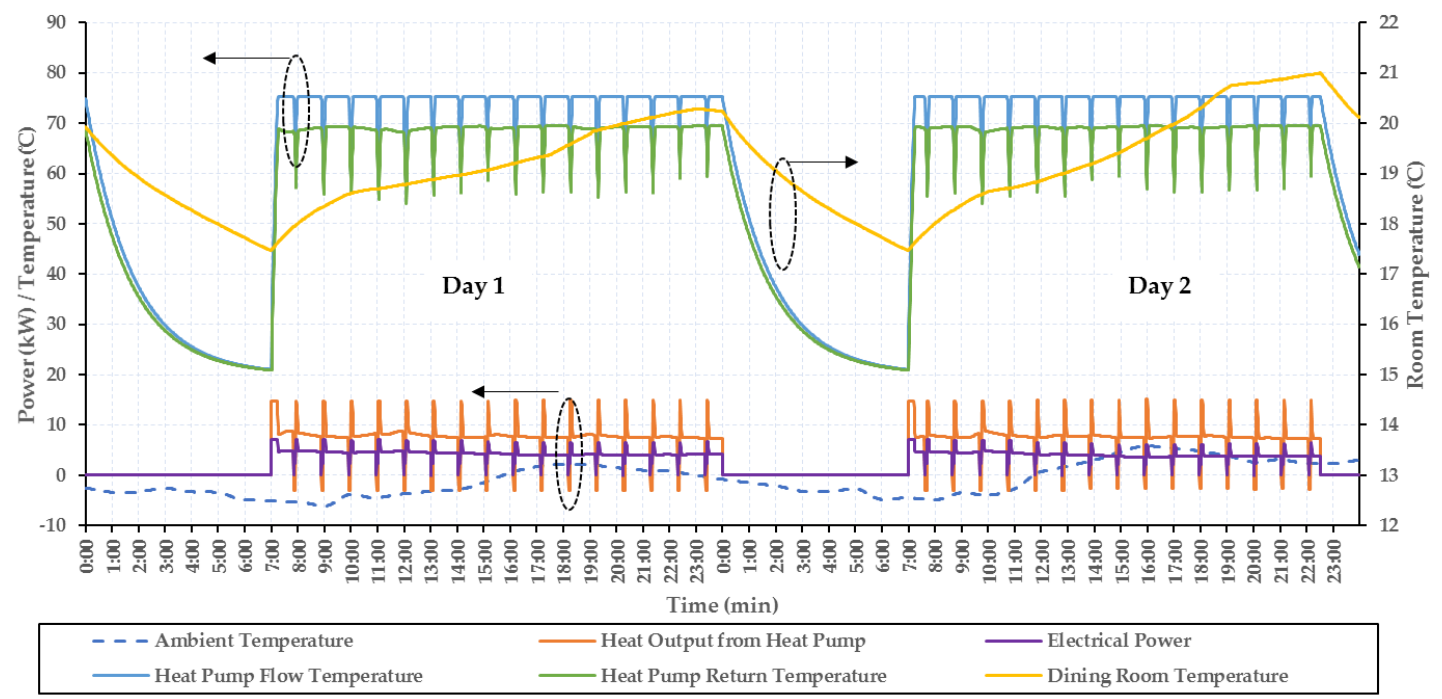

(a) Direct mode.

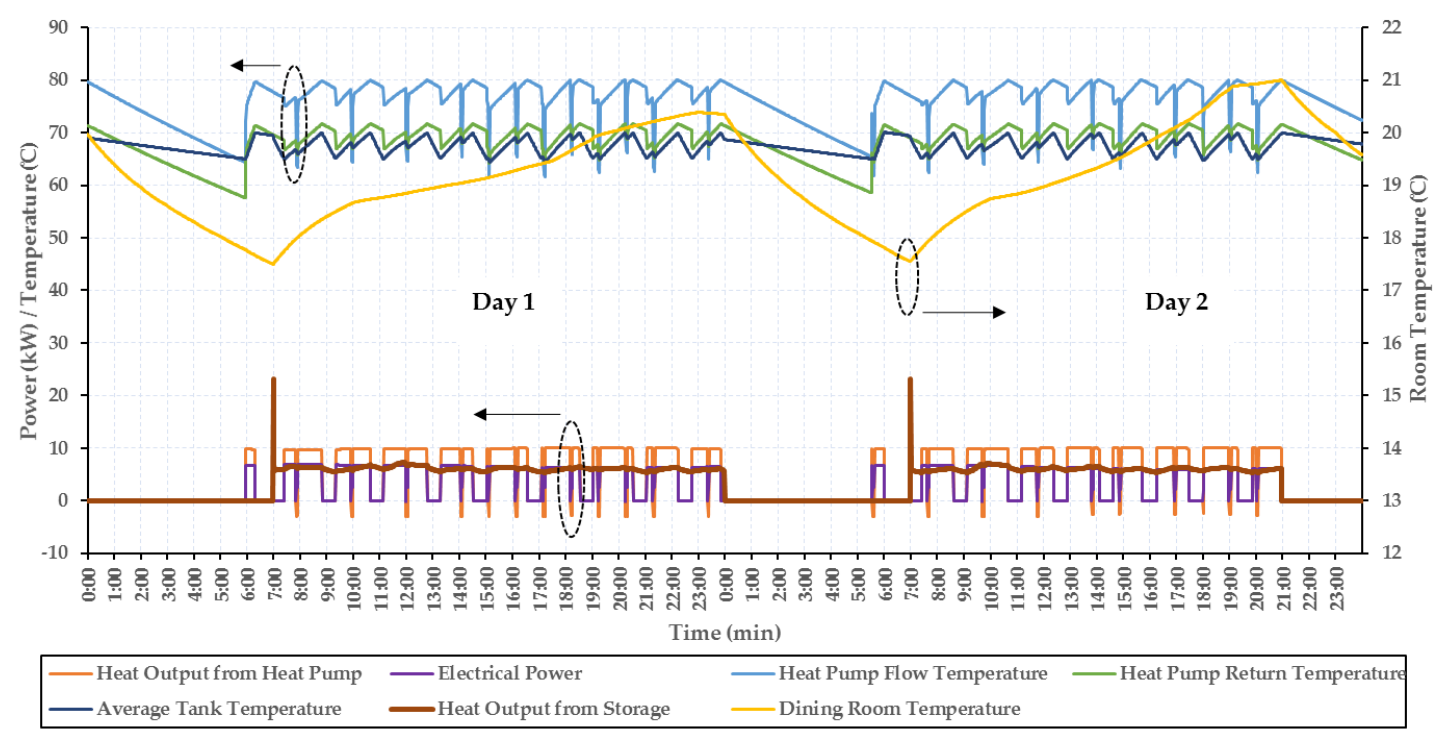

(b) Indirect mode.

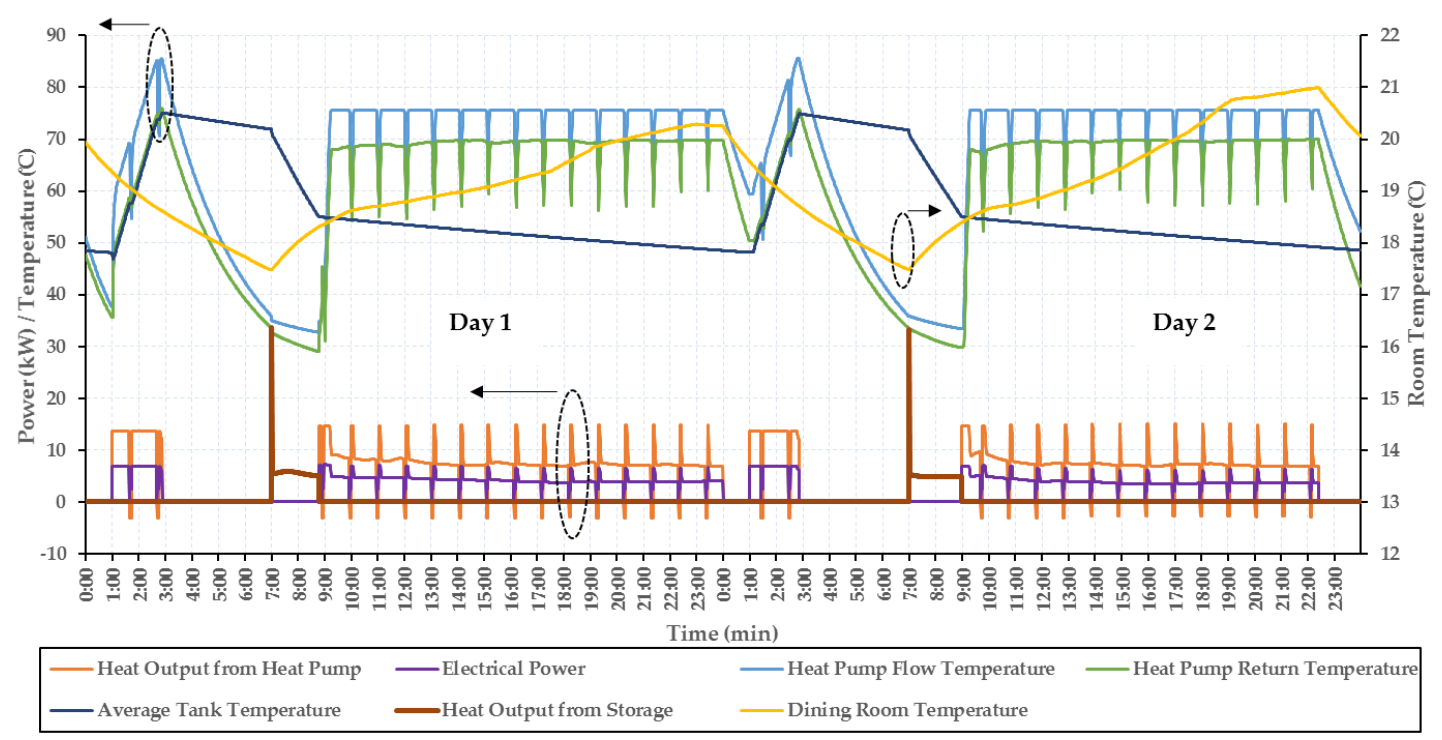

(c) Combined mode.

Figure 20: Simulated data of three modes in the same two typical winter days. 
Regarding direct mode and combined mode, direct mode also had a better performance. This is again due to the required higher flow temperatures to charge the storage associated with the heat pump in combined mode (see Fig. 20a and 20c). Furthermore, the heat pump in combined mode was active to top up the storage at night where the external air temperatures were lower than in day time, resulting in its COP reduction. The higher water lift temperature combined with the COP decrease in night time caused a lower annual COP (2.11) in comparison to the direct system (2.14), as reported in Table 12. For the system efficiency, again because of the parasitic losses of the storage tank, the yearly $\mathrm{COP}_{\text {sys }}$ of combined mode was roughly $11.3 \%$ lower than that of direct mode (Table 12).

Comparing the buffering to the load-shifting, the yearly COP of the buffering (1.66) was lower than the one of the load-shifting (2.11). This is because the heat pump in the combined mode charged the storage at night and then provided heat directly to the house in the day time (Fig. 20c), meaning that its COP deterioration due to the required high flow temperature was only affected for about two hours at night. Meanwhile, the CAWHP in the storage mode delivered high flow temperature all the time.

Although all systems could maintain the same thermal comfort (Table 12), there was an electric use penalty of the buffering (17304 kWh) which was approximately $46.9 \%$ and $30.1 \%$ higher than the heat pump in direct mode and combined mode, respectively. There are two main reasons why the buffering system consumed more energy than the night shifted load and the direct heating. Firstly, the heat pump had lower COP in the buffering system than in direct mode and combined mode. Secondly, the parasitic losses of the storage in the buffering system led the heat pump to consume more energy to compensate the supplied heat to the house. This did not occur in direct mode and happened in the shorter time during a day in combined mode.

The running costs are also calculated and presented in Table 12 based on the simulated energy consumption. According to the Economy 7 tariff used to calculate the operating cost of the heat pump in combined mode, the day rate was $£ 0.1666 / \mathrm{kWh}$, while the night rate was $£ 0.0931 / \mathrm{kWh}[41]$. It is clear in the table that combined mode could reduce heating costs for occupants compared to the other modes thanks to the benefit of the Economy 7 tariff. As for direct mode and indirect mode, direct mode was cheaper to run (about 46.9\%) than the one in the buffering mode. The reason for this is due to the lower efficiency of the heat pump and the parasitic losses of the tank, and future work will try to address this issue.

In Fig. 21, it is clear that there was cost penalty associated with the heat pump in 
the buffering system (indirect mode). Although the load-shifting (combined mode) could attain the cost savings compared to the other modes as mentioned above, its operating cost was still higher than those of gas boilers and $90 \%$ efficiency oil boiler. Therefore, a better demand-side management strategy should be carried out in the future study to make this CAWHP more cost competitive than the boilers.

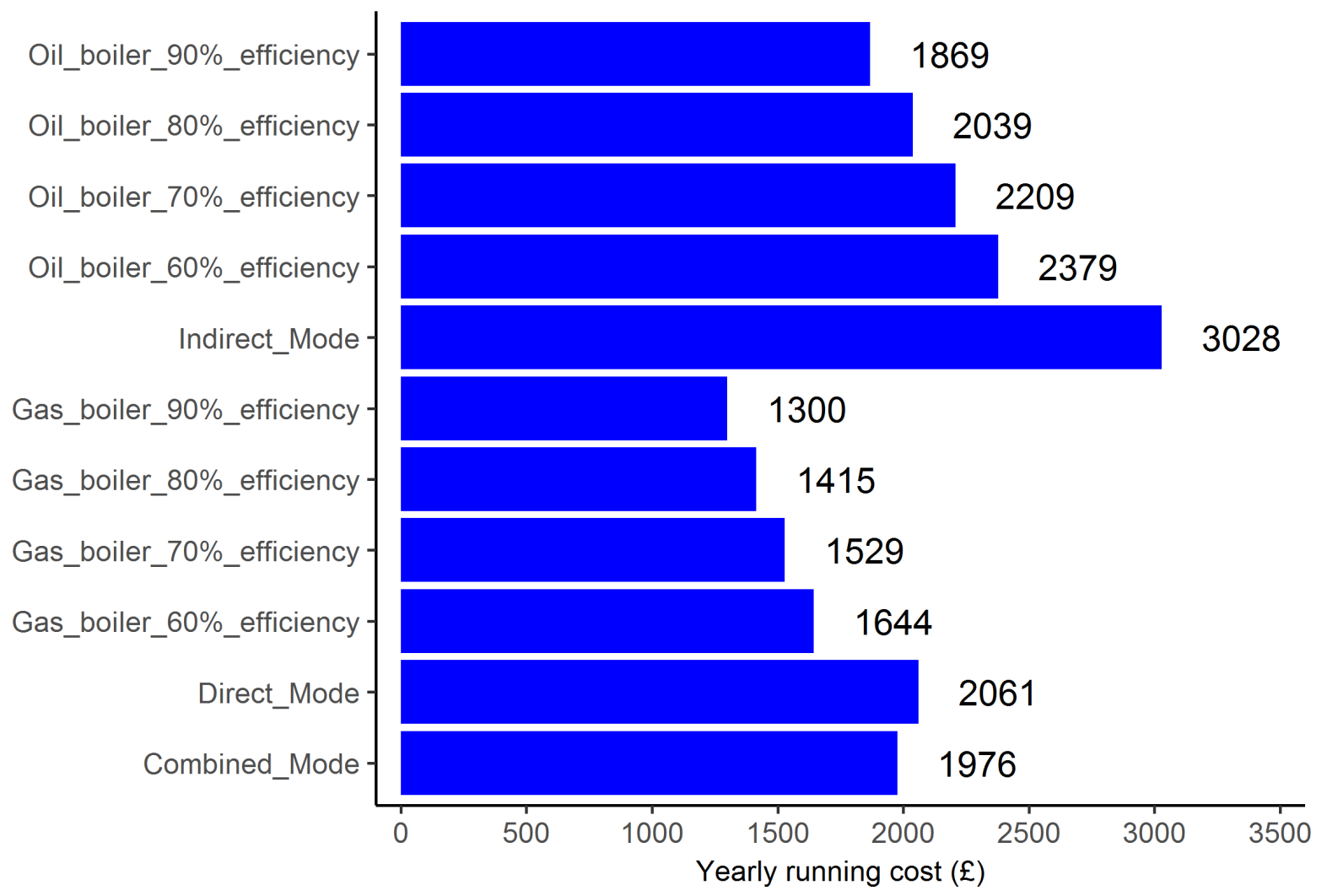

Figure 21: Comparison of annual running costs between the retrofit CAWHP in three operating modes and boilers.

Aside from the comparison discussed above, a summary of advantages and disadvantages of three operation modes are listed in Table 13. In direct mode, it took longer time to reach the set-point room temperature compared to the other modes. This is evidenced by looking at day 2 in Fig. 20, in which the room temperature reached $21^{\circ} \mathrm{C}$ at $22: 31$ (direct mode), 20:58 (indirect mode) and 22:24 (combined mode). There were two main reasons why this happened. First, the heat pump in direct mode operated with cold start in the morning, while the high heat output from the TES in both indirect mode and combined mode could allow the room temperature to reach its set-point earlier. Second, during defrost operation, heat was taken from the house to melt the ice on the outdoor coils according to the direct mode and combined mode, whilst regarding indirect mode, this heat was taken from the TES. This also explains why the period to reach thermal comfort of combined mode was 
shorter than indirect mode but longer than direct mode.

Table 13: Summary of advantages and disadvantages of three mode operations.

\begin{tabular}{|c|c|c|}
\hline & Advantage & Disadvantage \\
\hline Direct Mode & $\begin{array}{l}\text { - High efficiency } \\
\text { - Low energy utilisation }\end{array}$ & $\begin{array}{l}\text { - High running cost } \\
\text { - Longer time to reach thermal comfort } \\
\text { - Heat for defrost taken from house }\end{array}$ \\
\hline Indirect Mode & $\begin{array}{l}\text { - Faster to reach thermal comfort } \\
\text { - Heat for defrost taken from TES }\end{array}$ & $\begin{array}{l}\text { - High flow temperature to charge TES } \\
\text { - Low efficiency } \\
\text { - Parasitic losses of TES } \\
\text { - High running cost } \\
\text { - High energy utilisation }\end{array}$ \\
\hline Combined Mode & $\begin{array}{l}\text { - Good efficiency } \\
\text { - Take advantage of low electricity rate } \\
\text { - Low running cost } \\
\text { - Faster to reach thermal comfort }\end{array}$ & $\begin{array}{l}\text { - High flow temperature to charge TES } \\
\text { - Charge TES at night where ambient temperature is low } \\
\text { - Parasitic losses of TES } \\
\text { - High energy utilisation } \\
\text { - Heat for defrost taken from house }\end{array}$ \\
\hline
\end{tabular}

\section{Conclusions}

TRNSYS dynamic building simulations based on the laboratory and field results were used to assess the annual techno-economic performance of a CAWHP when retrofitted into a typical single-family house in different locations across the UK. The performance of the retrofit CAWHP coupled with TES in varied system configurations was also highlighted.

The model of a variable capacity CAWHP was developed, calibrated and validated based on the full load and part load curves informed by the field trial data, with defrost operation being incorporated outside the model. The heat pump model predictions were also compared with the laboratory data to confirm its reliability. The CAWHP model was then integrated into the TES model and whole building model before their predictions were validated against the field trial results.

The heat pump model integrated into the whole building model were simulated to predict the retrofit performance of the stand-alone CAWHP (without TES). The outcomes of the simulations were as follows:

- With the fixed outlet water temperature of $75^{\circ} \mathrm{C}$, the annual $\mathrm{COP}_{\text {sys }}$ was lowest (2.03) in Aviemore and highest (2.24) in Camborne. The annual energy consumption was be- 
tween $9427 \mathrm{kWh}$ and $13962 \mathrm{kWh}$. The turn-out yearly operating costs were from $£ 1650$ to $£ 2443$, and the carbon emissions were between $3624 \mathrm{~kg} /$ year and $5367 \mathrm{~kg} /$ year.

- Regarding the heat pump adopting weather compensation in Northern Ireland, an annual $\mathrm{COP}_{\text {sys }}$ improvement of approximately $9.1 \%$ and annual energy consumption savings of about $11.2 \%$ could be achieved compared to the fixed outlet water temperature. The monthly $\mathrm{COP}_{\text {sys }}$ enhancements could also be acquired between $5.4 \%$ and $23.9 \%$, with the highest in summer and the lowest in winter.

- The effect of weather compensation control on the heat pump annual performance primarily depended on climatic conditions. The annual COP sys improved by at least $6.7 \%$ and up to $11.9 \%$. The highest improvement was observed in Camborne, which has the mildest conditions, and the lowest in Aviemore, which has the most severe climate conditions.

- The retrofit CAWHP could not compete with gas boilers and $90 \%$ efficiency oil boilers regarding running costs. However, there were cost savings if low-efficiency oil boilers were replaced by the retrofit CAWHP.

- The retrofit CAWHP could reduce carbon emissions from $14 \%$ to $57 \%$ compared to the figures of gas and oil boilers, respectively.

The system performance of the retrofit CAWHP coupled with TES was also explored through simulations. The direct mode, indirect mode and combined mode were investigated. The direct mode obtained the highest annual efficiency $\left(\mathrm{COP}_{\text {sys }}\right.$ of 2.12$)$ followed by the shifted load (combined mode) $\left(\mathrm{COP}_{\text {sys }}\right.$ of 1.88), with the buffering system (indirect mode) having the worst performance $\left(\mathrm{COP}_{\text {sys }}\right.$ of 1.41). The reasons behind the low efficiencies in the buffering and the load-shifting modes were mainly due to the high flow temperature required to top up the tank and the parasitic losses of the storage. With regards to operating costs, combined mode proved a promising system as its running cost was lower than the other modes as a result of utilising the Economy 7 tariff. However, its operating cost was still higher than those of gas boilers and $90 \%$ efficiency oil boiler.

\section{Acknowledgement}

The authors would like to acknowledge the support funding from Research Councils UK (RCUK) under Interdisciplinary Centre for Storage, Transformation and Upgrading of Thermal Energy (i-STUTE) project [Grant number: EP/K011847/1]. This research has also been financed by Research Councils UK (RCUK)/ Engineering and Physical Sciences Research Council (EPSRC) through Small Smart Sustainable Systems for future Domestic 
Hot Water (4S-DHW) project [Grand number: EP/N021304/1]. Additionally, the authors thank for the financial contribution from the European Commission via H2020, CHESSSETUP project [Grant number: 680556]. Finally, the authors gratefully acknowledge the financial support from the European Union through Interreg VA SPIRE 2 project [Grant number: IVA5038].

\section{References}

[1] EU Directive on the Energy Performance of Buildings (recast) (2010/31/EU), Tech. rep., European Parliament.

[2] Energy Consumption in the UK July 2017, Tech. rep., Department for Business, Energy and Industrial Strategy, https://www.gov.uk/government/statistics/ digest-of-uk-energy-statistics-dukes-2017-main-report [Accessed 11-10-2018].

[3] Provisional estimates of UK Greenhouse Gas emissions for 2015, including quarterly emissions for 4th quarter 2015, Tech. rep., Department of Energy and Climate Change, https://www.gov.uk/government/statistics/ provisional-uk-greenhouse-gas-emissions-national-statistics-2015 [Accessed 11-10-2018].

[4] Emissions from Heat, Tech. rep., Department of Energy and Climate Change, https://www.gov.uk/ government/statistics/uk-emissions-from-heat [Accessed 11-10-2018].

[5] Carbon Footprint of Heat Generation, Tech. rep., Parliamentary Office of Science and Technology, https://researchbriefings .parliament.uk/ResearchBriefing/Summary/POST-PN-0523 [Accessed 11-10-2018].

[6] Climate change act 2008, Tech. rep., Parliament of the United Kingdom, http://www.legislation. gov.uk/ukpga/2008/27/pdfs/ukpga_20080027_en.pdf [Accessed 11-10-2018].

[7] N. Kelly, J. Cockroft, Analysis of retrofit air source heat pump performance: Results from detailed simulations and comparison to field trial data, Energy and Buildings 43 (1) (2011) 239-245. doi: 10.1016/j. enbuild.2010.09.018.

[8] Greenhouse gas reporting: conversion factors 2018 - GOV.UK, https://www.gov.uk/government/ publications/greenhouse-gas-reporting-conversion-factors-2018 (2018).

[9] S. J. Self, B. V. Reddy, M. A. Rosen, Geothermal heat pump systems: Status review and comparison with other heating options, Applied Energy 101 (2013) 341 - 348, sustainable Development of Energy, Water and Environment Systems. doi:https://doi.org/10.1016/j.apenergy.2012.01.048.

[10] F. Madonna, F. Bazzocchi, Annual performances of reversible air-to-water heat pumps in small residential buildings, Energy and Buildings 65 (2013) 299-309. doi:10.1016/j .enbuild.2013.06.016.

[11] S. Asaee, V. Ugursal, I. Beausoleil-Morrison, Techno-economic feasibility evaluation of air to water heat pump retrofit in the canadian housing stock, Applied Thermal Engineering 111 (2017) 936-949. doi:10.1016/j. applthermaleng.2016.09.117.

[12] K. Huchtemann, D. Müller, Evaluation of a field test with retrofit heat pumps, Building and Environment 53 (2012) 100 - 106. doi:https://doi.org/10.1016/j.buildenv.2012.01.013.

[13] L. Cabrol, P. Rowley, Towards low carbon homes - a simulation analysis of building-integrated air-source heat pump systems, Energy and Buildings 48 (2012) 127-136. doi:10.1016/j .enbuild.2012.01.019. 
[14] Detailed analysis from the first phase of the Energy Saving Trust's heat pump field trial 2012, Tech. rep., Department of Energy and Climate Change, https://www.gov.uk/government/publications/ greenhouse-gas-reporting-conversion-factors-2018 [Accessed 5-10-2018].

[15] J. Palmer, I. Cooper, United Kingdom Housing Energy Fact File, London, 2013, Tech. rep., Department of Energy and Climate Change.

[16] BS EN 442-2: Radiators and Convectors Part 2: Test Methods and Rating, Tech. rep., BSI.

[17] H. W. Jung, H. Kang, W. J. Yoon, Y. Kim, Performance comparison between a single-stage and a cascade multi-functional heat pump for both air heating and hot water supply, International Journal of Refrigeration 36 (5) (2013) 1431 - 1441. doi:https://doi.org/10.1016/j.ijrefrig.2013.03.003.

[18] J. Wu, Z. Yang, Q. Wu, Y. Zhu, Transient behavior and dynamic performance of cascade heat pump water heater with thermal storage system, Applied Energy 91 (1) (2012) 187 - 196 . doi:https: //doi.org/10.1016/j.apenergy.2011.09.020.

[19] S. S. Bertsch, E. A. Groll, Two-stage air-source heat pump for residential heating and cooling applications in northern u.s. climates, International Journal of Refrigeration 31 (7) (2008) 1282 - 1292. doi:https://doi.org/10.1016/j.ijrefrig.2008.01.006.

[20] K. Chua, S. Chou, W. Yang, Advances in heat pump systems: A review, Applied Energy 87 (12) (2010) 3611 - 3624. doi:https://doi.org/10.1016/j.apenergy.2010.06.014.

[21] H. Willem, Y. Lin, A. Lekov, Review of energy efficiency and system performance of residential heat pump water heaters, Energy and Buildings 143 (2017) 191-201. doi:10.1016/j.enbuild.2017.02. 023.

[22] L. Zhang, Y. Jiang, J. Dong, Y. Yao, Advances in vapor compression air source heat pump system in cold regions: A review, Renewable and Sustainable Energy Reviews 81 (2018) 353 - 365. doi:https: //doi.org/10.1016/j.rser.2017.08.009.

[23] H. Park, D. H. Kim, M. S. Kim, Thermodynamic analysis of optimal intermediate temperatures in r134a-r410a cascade refrigeration systems and its experimental verification, Applied Thermal Engineering 54 (1) (2013) 319 - 327. doi:https://doi.org/10.1016/j.applthermaleng.2013.01.005.

[24] H. Park, D. H. Kim, M. S. Kim, Performance investigation of a cascade heat pump water heating system with a quasi-steady state analysis, Energy 63 (2013) 283 - 294. doi:https://doi.org/10. $1016 / j$.energy . 2013.10.019.

[25] R. Soltani, I. Dincer, M. Rosen, Comparative performance evaluation of cascaded air-source hydronic heat pumps, Energy Conversion and Management 89 (2015) 577 - 587. doi:https://doi.org/10. 1016/j.enconman.2014.10.006.

[26] D. H. Kim, H. S. Park, M. S. Kim, Optimal temperature between high and low stage cycles for r134a/r410a cascade heat pump based water heater system, Experimental Thermal and Fluid Science 47 (2013) 172 - 179. doi:https://doi.org/10.1016/j.expthermflusci.2013.01.013.

[27] D. H. Kim, H. S. Park, M. S. Kim, The effect of the refrigerant charge amount on single and cascade cycle heat pump systems, International Journal of Refrigeration 40 (2014) 254 - 268. doi:https: //doi.org/10.1016/j.ijrefrig.2013.10.002.

[28] D. H. Kim, M. S. Kim, The effect of water temperature lift on the performance of cascade heat pump system, Applied Thermal Engineering 67 (1) (2014) 273 - 282. doi:https://doi.org/10.1016/j. applthermaleng.2014.03.036. 
[29] X. Ma, Y. Zhang, L. Fang, X. Yu, X. Li, Y. Sheng, Y. Zhang, Performance analysis of a cascade high temperature heat pump using r245fa and by-3 as working fluid, Applied Thermal Engineering 140 (2018) 466 - 475. doi:https://doi.org/10.1016/j.applthermaleng.2018.05.052.

[30] W. Wang, Z. Ma, Y. Jiang, Y. Yang, S. Xu, Z. Yang, Field test investigation of a double-stage coupled heat pumps heating system for cold regions, International Journal of Refrigeration 28 (5) (2005) 672679. doi:https://doi.org/10.1016/j.ijrefrig.2005.01.001.

[31] Evidence Gathering - Low Carbon Heating Technologies, Tech. rep., Department for Business, Energy and Industrial Strategy, https://assets.publishing.service.gov.uk/government/uploads/ system/uploads/attachment_data/file/565248/Heat_Pumps_Combined_Summary_report_-_ FINAL.pdf [Accessed 5-10-2018].

[32] N. N. Shah, C. Wilson, M. J. Huang, N. J. Hewitt, Analysis on field trial of high temperature heat pump integrated with thermal energy storage in domestic retrofit installation, Applied Thermal Engineering 143 (2018) 650 - 659. doi:https://doi.org/10.1016/j.applthermaleng.2018.07.135.

[33] N. J. Hewitt, Heat pumps and energy storage - the challenges of implementation, Applied Energy 89 (1) (2012) 37 - 44. doi:10.1016/j.apenergy .2010.12.028.

[34] A. Arteconi, N. Hewitt, F. Polonara, State of the art of thermal storage for demand-side management, Applied Energy 93 (2012) 371 - 389. doi:https://doi.org/10.1016/j.apenergy.2011.12.045.

[35] B. Alimohammadisagvand, J. Jokisalo, S. Kilpeläinen, M. Ali, K. Sirén, Cost-optimal thermal energy storage system for a residential building with heat pump heating and demand response control, Applied Energy 174 (2016) 275 - 287. doi:https://doi.org/10.1016/j.apenergy.2016.04.013.

[36] TRNSYS 17, a TRaNsient SYstem Simulation program - vol. 3- Component Library Overview, http: //www.trnsys.com/assets/docs/03-ComponentLibraryOverview.pdf [Accessed 5-10-2018].

[37] Daikin Altherma HT 11, Daikin UK Limited, http://www.daikin.co.uk/domestic/needs/heating/ air-water-heatpumps-ht/index .jsp [Accessed 06-10-2017].

[38] European Standard EN 14511-3: Air Conditioners, Liquid Chilling Packages and Heat Pumps with Electrically Driven Compressors for Space Heating and Cooling - Part 3 Test Methods, AFNOR, 2004.

[39] Northern Ireland House Condition Survey 2016: Main Report, Tech. rep., Northern Ireland Housing Excutive, https://www.gov.uk/government/statistics/ northern-ireland-house-condition-survey-2016-main-report [Accessed 5-10-2018].

[40] Energy Analysis Focus Report: A study of Hard to Treat Homes using the English House Condition Survey 2008, Tech. rep., BRE Housing, https://www.bre.co.uk/filelibrary/pdf/rpts/Hard_to_ Treat_Homes_Part_I.pdf [Accessed 5-10-2018].

[41] Economy 7 - The Consumer Council, http://www.consumercouncil.org.uk/sites/default/ files/2018-11/Economy\%207\%20Price\%20Comparison\%20Table\%2029\%20November\%202018.pdf [Accessed 11-01-2019].

[42] J. P. Holman, Experimental Methods for Engineers, Mc-Grall-Hill, The McGraw-Hill Companies, Inc., 1221 Avenue of the Americas, New York, NY 10020, 2012.

[43] TESS component libraries, http://www.trnsys.com/tess-libraries [Accessed 10-06-2018].

[44] The R Project for Statistical Computing, https://www.r-project.org/ [Accessed 08-10-2018].

[45] C. Underwood, M. Royapoor, B. Sturm, Parametric modelling of domestic air-source heat pumps, Energy and Buildings 139 (2017) 578 - 589. doi:https://doi.org/10.1016/j.enbuild.2017.01. 
026.

[46] M. E. Baster, Modelling the performance of air source heat pump systems, Master's thesis, Department of Mechanical Engineering, University of Strathclyde Engineering (2011).

[47] K. Ogawa, N. Tanaka, M. Takeshita, Performance improvement on plate fin-and-tube heat exchangers under frosting conditions, in: ASHRAE Transactions 99 (1993), 1993.

[48] W. A. Miller, Laboratory evaluation of the heating capacity and efficiency of a high-efficiency, air-to-air heat pump with emphasis on frosting/defrosting operation, NASA STI/Recon Technical Report N 83.

[49] O. QUEVILLON, L. Lamarche, S. Kajl, Couplage d'un Échangeur air-sol pour augmenter la performance en chauffage d'une pompe À chaleur À air, in: XIIIème Colloque Interuniversitaire FrancoQuébécois sur la Thermique des Systèmes 22-24 mai 2017, LUSAC Saint-Lô, France, 2017.

[50] SketchUp, https://www. sketchup.com/[Accessed 10-06-2018].

[51] L. B. N. Laboratory, Genopt, https://simulationresearch.1bl.gov/GO [Accessed 06-10-2018].

[52] A. Cacabelos, P. Eguía, J. L. Míguez, E. Granada, M. E. Arce, Calibrated simulation of a public library hvac system with a ground-source heat pump and a radiant floor using trnsys and genopt, Energy and Buildings 108 (2015) 114 - 126. doi:https://doi.org/10.1016/j.enbuild.2015.09.006.

[53] A. Safa, A. Fung, R. Kumar, Performance of two-stage variable capacity air source heat pump: Field performance results and trnsys simulation, Energy and Buildings 94 (2015) 80-90. doi:10.1016/j. enbuild.2015.02.041.

[54] A. Safa, A. Fung, R. Kumar, Comparative thermal performances of a ground source heat pump and a variable capacity air source heat pump systems for sustainable houses, Applied Thermal Engineering 81 (2015) 279-287. doi:10.1016/j.applthermaleng.2015.02.039.

[55] Fuel Efficiency Degree Days, Blackhorse Road, London SE8 5JH, 1993.

[56] Ofgem, Domestic Renewable Heat Incentive (RHI), https://www.ofgem.gov.uk/ environmental-programmes/domestic-rhi [Accessed 06-10-2018].

[57] Electricity price comparison table - The Consumer Council, http://www.consumercouncil.org.uk/ sites/default/files/2018-11/Electricity_Price_Comparison_Table_8_November_2018.pdf.

[Accessed 11-01-2019].

[58] Greenhouse gas reporting: conversion factors 2017 - GOV.UK, Tech. rep., Department for Business, Energy and Industrial Strategy, https://www.gov.uk/government/publications/ greenhouse-gas-reporting-conversion-factors-2017 [Accessed 03-02-2018].

[59] Home Heating Oil, http://www.consumercouncil.org.uk/consumers/save-money/energy/ home-heating-oil [Accessed 08-10-2018].

[60] Gas price comparison for Greater Belfast and Larne area 2018, http://www.consumercouncil.org. uk/search?search_api_fulltext=filestore+documents+Gas+Price+Comparison+Table+April+ 2018+pdf [Accessed 08-10-2018].

[61] Daikin UK Price List - January 2018, http://www.oceanairuk.com/wp-content/uploads/2018/01/ Daikin_Price_List_2018-19.pdf [Accessed 10-03-2018] (2018).

[62] System Solution Pack Price List - March 2018, https://siteassets.pagecloud.com/freedomhp/ downloads/2018_Hitachi_FHP_price_list-ID-3676ae8d-36d1-4579-d6a9-d41ad9957f3d.pdf [Accessed 10-03-2018] (2018).

[63] N. Kelly, P. Tuohy, A. Hawkes, Performance assessment of tariff-based air source heat pump load shifting 
in a uk detached dwelling featuring phase change-enhanced buffering, Applied Thermal Engineering 71 (2) (2014) 809-820. doi:10.1016/j.applthermaleng.2013.12.019. 